Research Article

\title{
Difference Analysis of Disaster Types and Grading Control Technologies for Risk of Caving of Coal Roadway Roof
}

\author{
Jicheng Feng, ${ }^{1}$ Zhiheng Cheng $\mathbb{D},{ }^{1,2}$ Hongbing Wang, ${ }^{3}$ Jianjun Shi, ${ }^{1}$ Haoyu Shi, \\ and Shuaifeng Yin ${ }^{1}$ \\ ${ }^{1}$ School of Safety Engineering, North China Institute of Science and Technology, Beijing 101601, China \\ ${ }^{2}$ NCIST Zhongan Technology (Beijing) Co., Ltd, Beijing 101601, China \\ ${ }^{3}$ State Key Laboratory of High-Efficiency Mining and Safety of Metal Mines, Ministry of Education, \\ School of Civil and Resource Engineering, University of Science and Technology Beijing, Beijing 100083, China
}

Correspondence should be addressed to Zhiheng Cheng; an958158@163.com

Received 3 February 2021; Revised 15 March 2021; Accepted 19 March 2021; Published 14 April 2021

Academic Editor: Feng Du

Copyright (C) 2021 Jicheng Feng et al. This is an open access article distributed under the Creative Commons Attribution License, which permits unrestricted use, distribution, and reproduction in any medium, provided the original work is properly cited.

\begin{abstract}
In view of the problem of a caving roof along different parts of the same roadway in a mine, this study classifies the mechanical characteristics of the local instability of the roof based on differences in the rock mass media and types of damage. We determine the factors influencing the quantitative relationship between the failure height of the roof and the environment to establish an indicator system for classifying the grades of risk of the roof caving. This is used to predict the height at which the roof caves along the roadway in a coal seam through fuzzy variable weighting analysis. We also develop software for the grading system of risks of caving of the roof and draw a grading map to represent this risk for a roadway in coal seam No. III in Zhaogu Coal Mine No. 2 in Jiaozuo City of Henan Province, China. According to the zoning characteristics of the coal mine, a targeted support design test is carried out in the same intake airway of working face 11030 of the mine. The results show that the proposed classification method conforms to safe practices in underground mining. The stability of the roadway during service and the grades determined using the proposed method were consistent. This has important theoretical significance and practical value for designing support for roadways and timely reinforcements in areas with a high-risk grade to guarantee the safe operation of coal mines.
\end{abstract}

\section{Introduction}

Mining disasters have a serious impact on the safe production of coal mines. Among the different kinds of mining disasters, those pertaining to roadway roofs are characterized by a high frequency and a large number of deaths because of which reasonable and targeted roof support has become a focus of research in the context of controlling safe production in coal mines. To identify areas at high risk of caving roofs along a roadway, it is important to study the mechanism of caving and analyze the stability of rock surrounding the roadway. Chen and Chen [1] claimed that the factors influencing the stability of the roof of a roadway can be classified into four categories, i.e., natural geological factors, factors related to engineering quality, the impact of mining engineering, and factors resulting from operations by technical personnel that are not in compliance with roof safety regulations. Based on the stress distribution in its rock surrounding, Gou and Hou [2] noted that the caving of the roof of a roadway supported by anchor bolts can be classified into two categories. One involves the slipping down of the anchorage in the roof above two sidewalls of the roadway due to shear failure and the other involves caving induced by the compression failure of the anchorage on the roof of the roadway. Xu et al. [3] claimed that the properties of roof strata are important factors delaying the layered roof caving of roadways, whereas changes in the thickness of soft rock are the most important factor. Jia and Wang [4] claimed that the ratio of the thickness to the span of rock beams has important effects on the layered roof caving of roadways. Huang et al. [5] claimed that the coefficient $\lambda$ of lateral pressure of the surrounding rock is the main factor influencing the failure of rock mass in layered roofs of the 
roadway. In accordance with characteristics of rock surrounding the roadway, Jia [6] divided the causes of caving into 12 subcategories (in four major categories) and concluded that the primary cause of caving is an inferior combination of strata. Yang [7] noted that, owing to vertical stress, joints and fractures in layered roof strata convert the layered rock mass into an articulated arch, which damages the bearing structure. For the rock mass in a roof under horizontal stress, the articulated arch is crushed and broken. Under vertical and horizontal stresses, a roof with a layered structure of the coal roadway finally forms a combined articulated arch structure.

When classifying the stability of its surrounding rock, a coal mine or a coal seam is generally researched from a macroscopic perspective [8-28]. In most roadways, excessive support is used to control the caving of the roof, which increases cost and sometimes leads to caving accidents. Few studies have examined methods of classifying the same roadway into different risk grades of roof caving. By combining the classification of a layered roof of the roadway with parameters of the supporting bodies, Liu and Ma [29] constructed a mechanical model for the stability of the roof strata and analyzed the main factors influencing the caving of the roof. According to different grades, a reasonable and targeted support was used.

In terms of its morphology, the roof of a roadway in a coal seam caves not simply due to the failure and collapse of the layered rock mass structures but also as a result of changes in them under the effects of various factors, such as long-term diagenesis and tectonic movement. The diversity of rock mass structures causes the roadway to feature various rock mass media because of which the mechanical mechanisms of roof caving, height at which the roof caves, influential factors, and geometric morphology of the failure zone vary from place to place. An analysis of the stability of the roof of the roadway should be based on objective mechanical properties and structural characteristics of the surrounding rock mass. By analyzing and studying rock mass media in the roof of the roadway, this study builds a relationship between the types of disasters in the roadway and summarizes the characteristics of different rock mass media. Moreover, roof caving is classified into four types: the falling of local blocks from the roof of the roadway due to fractured surrounding rock mass, the caving of a composite roof with weakly bonded and layered surrounding rock mass, caving in a butterfly-shaped plastic zone of the roadway with fractured surrounding rock mass, and roof leakage in the roadway with a loose surrounding rock mass [30-32], as shown in Figure 1.

Based on the differences in rock mass media and types of disaster in the roof of the coal roadway, we classified and clarified the quantitative relationships between such accidents and the environment of the rock mass and the mechanical characteristics of local instability of the roof. We use this to establish an indictor system for classifying the grades of risk of the caving roof. This is used to predict the height of caving of the roof of the roadway in a coal seam through the fuzzy mathematical method. In addition, according to different heights of caving, the risk of the roof caving is graded and software for the risk grading system is developed. We also generate a zoning map for the grade of risk and propose targeted support design. This has an important theoretical significance and practical value for guiding the design of support along the roadway of a mine and reducing the probability of accidents to ensure safe production.

\section{Difference Analysis of Types of Damage to Roofs of Coal Roadways}

2.1. Falling Local Blocks from Roof of Roadway with Fractured Surrounding Rock Mass. Figure 2(a) shows a hexahedral block structure in the roof of the roadway of a mine. In this structure, two pairs of structural planes P1 and P4 and P2 and P3 are parallel to each other and cut the roadway into a hexahedral block structure. P1 is a free face, as shown in Figure 2(b).

In this structure, A, as a key block, undergoes shear slip or falling along the weak plane under dead weight. According to the limit equilibrium principle, a mechanical model for the stability of local blocks in a roadway roof with fractured surrounding rock is built, as shown in Figure 3.

Assuming that the block is of unit length, its gravity $G$ is as follows:

$$
G=\gamma V=\gamma S_{\text {梯 }}=\gamma h \frac{\left(2 l-\left(h / \tan a_{A}\right)-\left(h / \tan a_{B}\right)\right)}{2},
$$

where $l$ represents the length of the free face, $a_{A}$ and $a_{B}$ indicate the angles of the free face with the two weak structural planes, and $G, \gamma$, and $h$ denote the weight of the block, the volume force, and the height of the block, respectively.

$\mathrm{X}$ and $\mathrm{Y}$ as applied on the block are expressed as follows:

$$
\left\{\begin{array}{l}
X=\sigma_{x} h, \\
Y=\sigma_{y}\left(l-\frac{h}{\tan a_{A}}-\frac{h}{\tan a_{B}}\right) .
\end{array}\right.
$$

assumed thatIt is $\left\{\begin{array}{l}\sigma_{x}=\lambda \gamma H \\ \sigma_{y}=\gamma H\end{array}\right.$, where $\sigma_{x}, \sigma_{y}, \gamma, H$, and $\lambda$ indicate theIt is horizontal stress, vertical stress, volume force, burial depth of the roadway, and coefficient of lateral pressure, respectively.

Based on the equilibrium condition of the minimum ultimate strength of rock blocks, the following formulae are obtained:

$$
\begin{gathered}
\sum Y=0, \\
F_{1} \sin a_{A}+F_{2} \sin a_{B}=G+Y,
\end{gathered}
$$

where $F_{1}=N_{1} \times \tan \varphi=X \sin a_{A} \times \tan \varphi_{A}$ and $F_{2}=N_{2}$ $\times \tan \varphi=X \sin a_{B} \times \tan \varphi_{B}$.

$F_{1}$ and $F_{2}$ represent the frictional forces of the two weak planes, $N_{1}$ and $N_{2}$ indicate the normal pressures on the two weak planes, and $\varphi_{A}$ and $\varphi_{B}$ denote their frictional angles, respectively:

$$
X \sin ^{2} a_{A} \tan \varphi_{A}+X \sin ^{2} a_{B} \tan \varphi_{B}=Y+G .
$$

If block A slips along the two planes, the conditions for stability are presented as follows: 

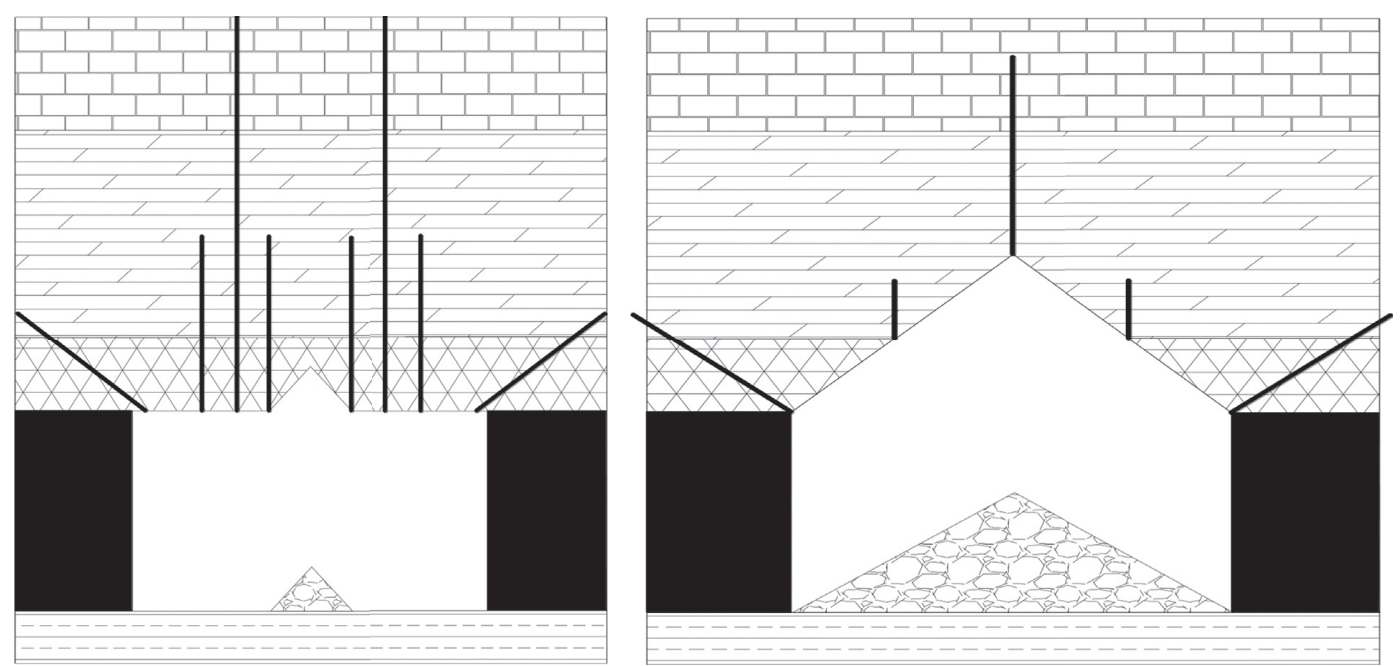

(a)
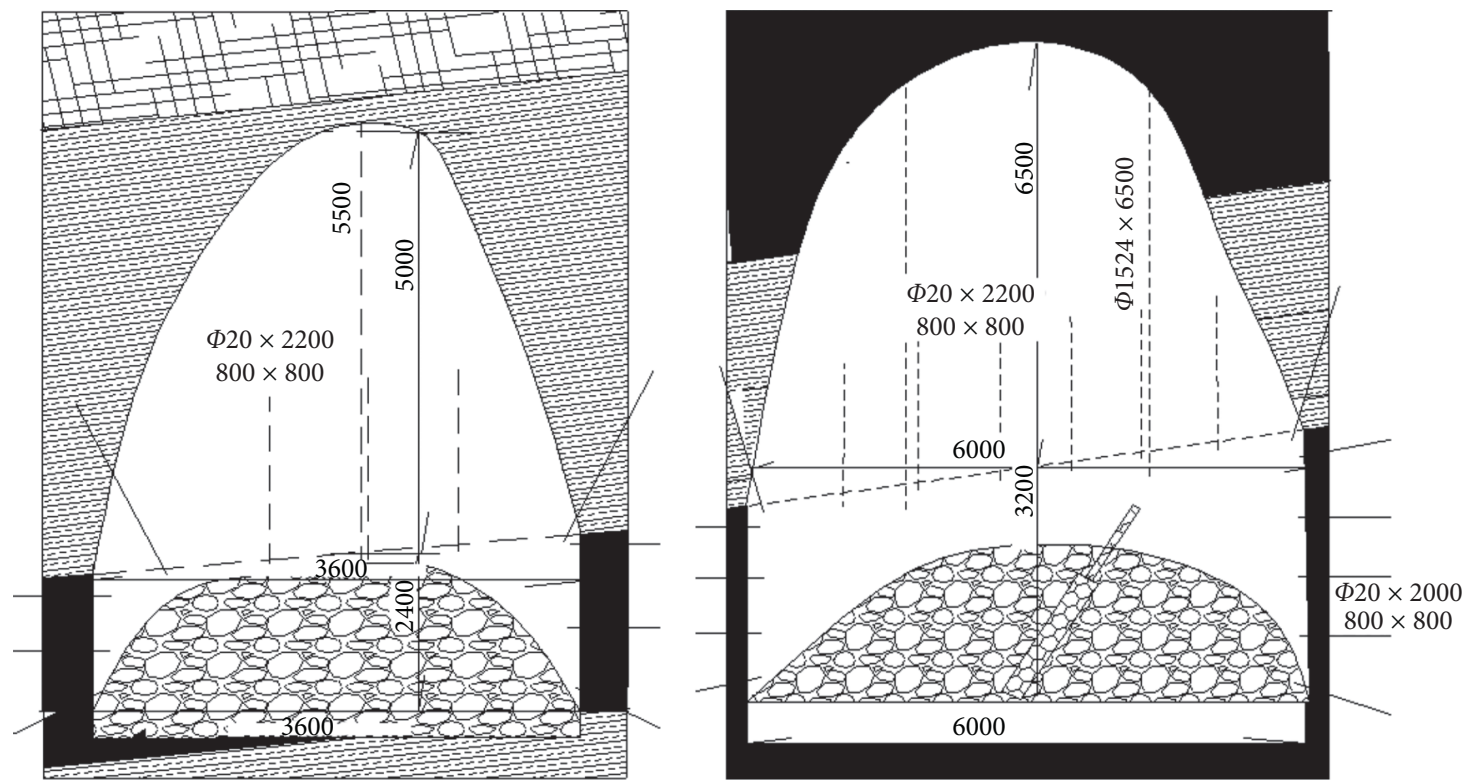

(b)
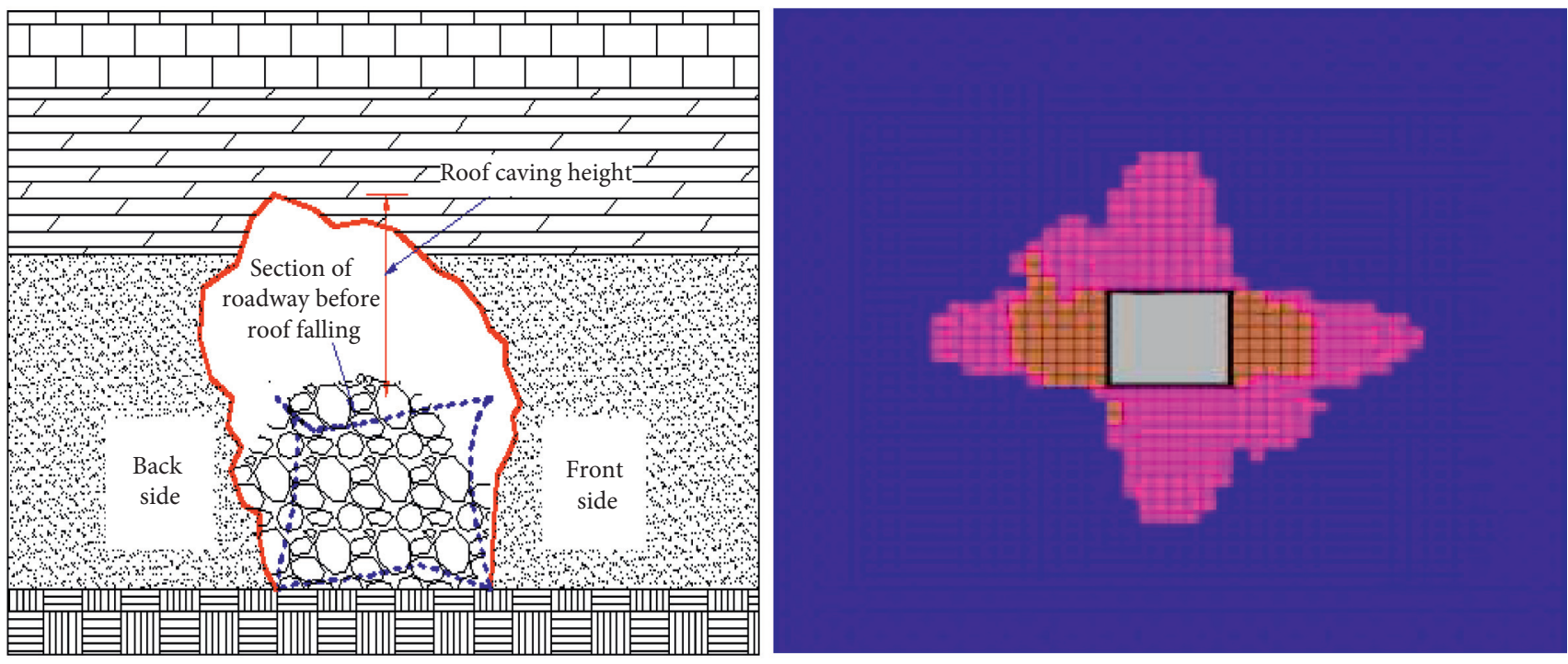

(c)

Figure 1: Continued. 


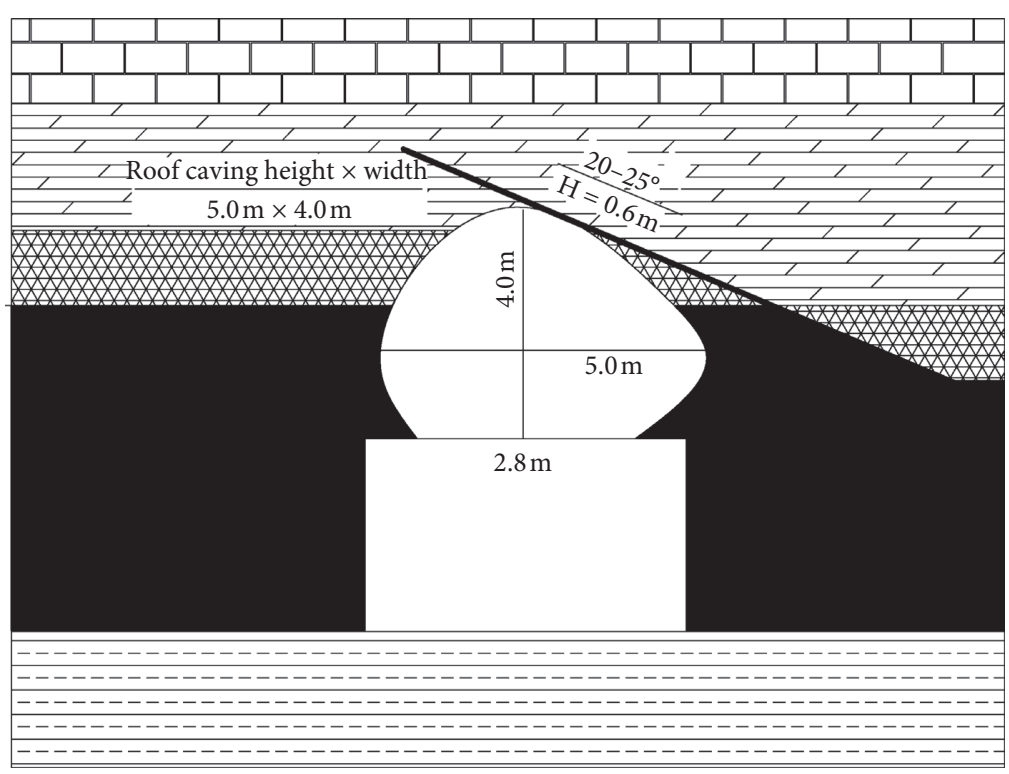

(d)

FIGURE 1: Types of disasters due to the caving of the roof of a roadway: (a) examples of caving caused by local block falling between anchor bolts (cables) and a cross-sectional block falling; (b) examples of roof caving induced by an inferior combination of strata of composite layered roofs; (c) examples of caving in a butterfly-shaped plastic zone; (d) an example of caving accident of a loose and fractured roof owing to improper support for small implicit faults.

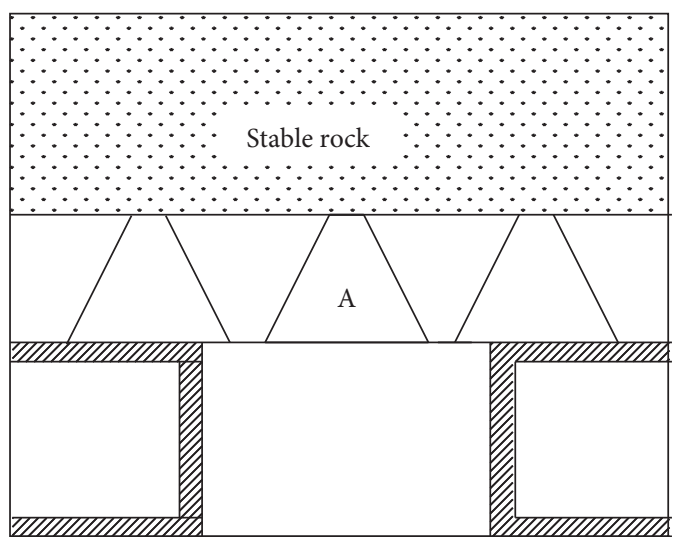

(a)

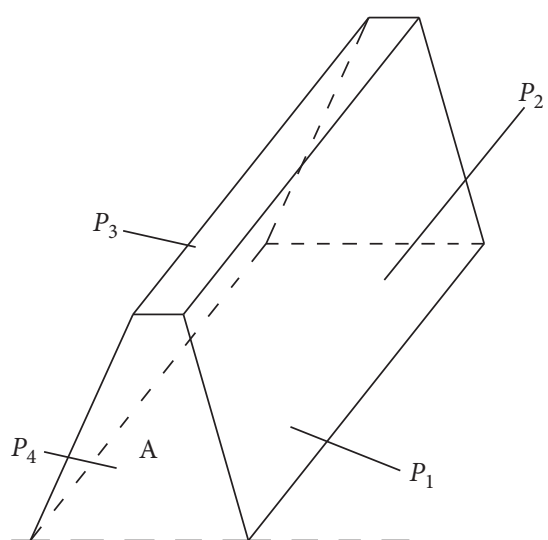

(b)

Figure 2: Hexahedron block structure of the roof of a roadway.

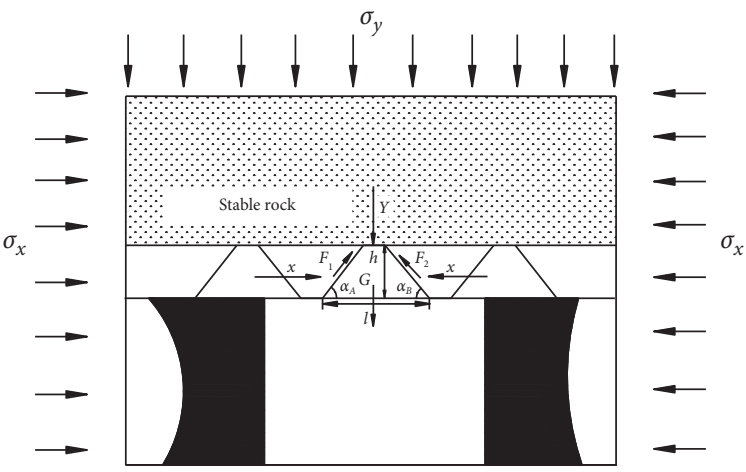

FIGURE 3: Model for analyzing the stability of the hexahedron rock blocks in a roof. 


$$
\begin{aligned}
X \sin ^{2} a_{A} \tan \varphi_{A}+X \sin ^{2} a_{B} \tan \varphi_{B} & \geq Y+G, \\
\sigma_{x} h \times\left(\sin ^{2} \alpha_{A} \tan \varphi_{A}+\sin ^{2} \alpha_{B} \tan \varphi_{B}\right) & =\sigma_{y}\left(l-\frac{h}{\tan a_{A}}-\frac{h}{\tan a_{B}}\right)+\gamma h\left(2 l-\frac{h}{\tan a_{A}}-\frac{h}{\tan a_{B}}\right), \\
\sigma_{y}\left(l-\frac{h}{\tan a_{A}}-\frac{h}{\tan a_{B}}\right) & \gg \gamma h \frac{\left(2 l-\left(h / \tan a_{A}\right)-\left(h / \tan a_{B}\right)\right)}{2}, \\
\sigma_{x} h \times\left(\sin ^{2} \alpha_{A} \tan \varphi_{A}+\sin ^{2} \alpha_{B} \tan \varphi_{B}\right) & =\sigma_{y}\left(l-\frac{h}{\tan a_{A}}-\frac{h}{\tan a_{B}}\right), \quad a_{A} \neq 0, a_{B} \neq 0, \text { thus, } \frac{1}{\tan a_{A}}+\frac{1}{\tan a_{B}} \neq 0 \mid, \\
l & =\frac{l}{\left[\lambda \times\left(\sin ^{2} \alpha_{A} \tan \varphi_{A}+\sin ^{2} \alpha_{B} \tan \varphi_{B}\right)+\left(1 / \tan a_{A}\right)+\left(1 / \tan a_{B}\right)\right]} .
\end{aligned}
$$

If there is no frictional force of the rock block, free falling occurs only under gravity $G$.

Equation (6) shows that the falling height $h$ of the block has an important correlation with the block structure and is mainly affected by length $l$ of the free face, dip angle $\alpha$ of the structural plane, frictional angle $\varphi$, and coefficient $\lambda$ of lateral pressure. Furthermore, the height of the rock mass when stable is directly proportional to the length of the free face; that is, as the length of the free face of the block increases, the height of the stable block rises. This reasonably explains why small blocks generally fall in the transverse direction of the roadway, with the falling height generally not greater than the length of the anchor bolts, while large blocks usually fall in the longitudinal direction of the roadway, with a high risk of falling over the large caving area of the roof and causing serious damage.

\subsection{Composite Caving of Roof of Roadway with Layered Surrounding Rock Mass}

2.2.1. Mechanical Analysis of Fracturing of Layered Roof Strata of the Roadway. In general, the limit span corresponding to shear stress is much larger than that generated by the bending of the beam. Therefore, in modeling and calculations, whether the strata are unstable is determined according to the limit span and bearing capacity of the rock beams:

(1) Once the roadway has been excavated, the rock surrounding it is less damaged in a short period, and the mechanical model of rock beams in the roof of the roadway should be calculated according to the clamped-clamped beam at the outset, as shown in Figure 4.

When calculating the limit span of strata according to the model, the analysis should start from the first stratum of the roof of the roadway. If the limit span of rock beams in this stratum is smaller than the span of the roadway, the first stratum is unstable and causes instability and collapse. If its limit span is larger than the span of the roadway, the calculation is carried out based on the mechanical model in Figure 4, until a stable stratum is found.

In the calculation in accordance with clampedclamped beams, as the minimum ultimate tensile strength $\sigma_{t x}$ of the stratum is smaller than the maximum tensile stress $\sigma_{\max }$, the stratum is fractured and instability occurs. In this case, the clampedclamped beam is fractured and the limit span of the stratum with the minimum strength is expressed as follows:

$$
L_{x}=h_{x} \sqrt{\frac{2 \sigma_{t x}}{q_{x}}}
$$

where $h_{x}, L_{x}$, and $\sigma_{t x}$ indicate the thickness, span, and unidirectional tensile strength of the $x$ th stratum, respectively.

According to equation (1), the limit span $L_{x}$ of the $x$ th stratum with the minimum ultimate strength is related to the thickness $h_{x}$ of the stratum, unidirectional tensile strength $\sigma_{t x}$, and the imposed load $q_{x}$. Of them, the limit span $L_{x}$ of the stratum with the minimum ultimate strength is directly proportional to the thickness $h_{x}$ of this stratum and its unidirectional tensile strength $\sigma_{t x}$ and reversely proportional to the imposed load $q_{x}$. This indicates that if the other factors remain unchanged, the greater the thickness and tensile strength of the stratum are, the larger the limit span of the stratum with the minimum strength and the more stable it is. The larger the imposed load $q_{x}$ is, the greater the imposed load borne by the stratum is, and the smaller the limit span of the stratum with the minimum strength is, so that it can more easily become unstable.

In terms of factors influencing the limit span, past research [29] has shown that the burial depth $f_{m}$, abnormal in situ stress $f_{d}$, and integrity $f_{w}$ of the rock mass can weaken the limit span of the strata. When calculating the limit span of the strata with the minimum strength, the following factors are considered and introduced into the calculation: 


$$
[L]=h_{x} f_{w} \sqrt{\frac{2 \sigma_{t x}}{q_{x} f_{m} f_{d}}} .
$$

In conclusion, when the limit span $[L]$ of the stratum is smaller than the span $L$ of the roadway, that is, $[L]=h_{x} f_{w} \sqrt{\left(2 \sigma_{t x} / q_{x} f_{m} f_{d}\right)}<L$, the stratum becomes unstable and collapses. As the limit span $[L]$ of the stratum is larger than the span $L$ of the roadway, that is, $[L]=h_{x} f_{w} \sqrt{\left(2 \sigma_{t x} / q_{x} f_{m} f_{d}\right)}<L$, a lintel structure is formed by the stratum. The mechanical model is shown in Figure 5.

(2)If the limit span of the stratum is larger than the span of the roadway, a lintel structure is formed. When the inserted section is larger than the span $L$ of the roadway, it tends to be a clamped-clamped beam and the stratum is stable. When the inserted section is not long, the lintel structure formed is somewhere between a clamped-clamped beam and a simply supported beam. The model of the lintel structure established by the roof stratum is calculated according to Figure 5, and its bending moment is shown in Figure 6.

The maximum positive and negative bending moments of the rock beam are separately shown as follows:

$$
\begin{aligned}
& M_{\max }^{+}=\frac{q_{x}[L]}{2} \times \frac{L}{2}-\frac{q_{x}[L]^{2}}{8}, \\
& M_{\max }^{-}=-\frac{q_{x}}{2}\left(\frac{[L]-L}{2}\right)^{2} .
\end{aligned}
$$

In accordance with normal stress at any point of the beam,

$$
\sigma=\frac{12 M_{x} y_{x}}{h_{x}^{3}}
$$

Therefore, the following formulae are obtained:

$$
\begin{aligned}
& \sigma_{\max }^{+}=\frac{12 M_{\max }^{+}\left(h_{x} / 2\right)}{h_{x}^{3}}=\frac{6 \times\left(\left(q_{x}[L] / 2\right) \times(L / 2)-\left(q_{x}[L]^{2} / 8\right)\right)}{h_{x}^{2}}=\frac{6 q_{x}[L] \times L-3 q_{x}[L]^{2}}{4 h_{x}^{2}}=\frac{3 q_{x}[L] \times(2 L-[L])}{4 h_{x}^{2}} \\
& \sigma_{\max }^{-}=\frac{12 M_{\max }^{-}\left(h_{x} / 2\right)}{h_{x}^{3}}=\frac{6 \times\left[-\left(q_{x} / 2\right)([L]-L / 2)^{2}\right]}{h_{x}^{2}}=\frac{-3 q_{x}([L]-L)^{2}}{4 h_{x}^{2}} .
\end{aligned}
$$

As the limit span $[L]$ is not large in relation to the span $L$ of the roadway, the structure tends to be a simply supported beam, and the stress $\sigma_{\max }^{-}$is much smaller relative to the failure strength $\sigma_{t}$ of the beam. The beam thus cannot be fractured at the articulated point. Therefore, when $\sigma_{\max }^{+}<\sigma_{t x}$, namely, $\left(3 q_{x}[L] \times(2 L-[L]) / 4 h_{x}^{2}\right) \geq \sigma_{t x}$, the middle of the beam is not broken and the stratum is stable. When $\sigma_{\max }^{+}>\sigma_{t x}$, that is, $\left(3 q_{x}[L] \times(2 L-[L]) / 4 h_{x}^{2}\right) \geq \sigma_{t x}$, the middle of the beam is broken to form a classic articulated structure of the block in Figure 7 [26].

The sliding and instability of the articulated structure of blocks are as

$$
\frac{h_{x}}{([L] / 2)} \leq \frac{1}{2} \tan (\varphi-\theta),
$$

where $\varphi$ represents the frictional angle between the blocks. In general, $\varphi=38^{\circ} \sim 45^{\circ}$ and $\tan \varphi=0.8 \sim 1$. Moreover, $[L]$ and $h_{x}$ indicate the limit span and thickness of the stratum, respectively.

The deformation and instability of the articulated structure of the block are presented as

$$
\sigma_{p}=\frac{2 q_{x} \times i^{2}}{(1-i \times \sin \alpha)^{2}}
$$

where $i=([L] / 2) / h_{x}$ and $\alpha$ and $\sigma_{p}$ denote the angle of rotation of the rock mass and the extrusion stress, respectively. Given the biting point is in a plastic state, the formula is similar to $\Delta=([L] / 2) \times \sin \alpha$; thus, the angle of rotation can be calculated according to this formula, in which $\Delta$ represents the maximum subsidence of the roof of the roadway.

\subsubsection{Basis of Determining Stable Strata of Layered Roof}

(1) Analysis of imposed load $q_{x}$. The load imposed by rock beams on the $x$ th stratum of the roof of the roadway is $q_{x}$ and comprises three parts, i.e., dead weight of the stratum, load generated by interactions between the overlying strata, and action of unstable underlying strata on the $x$ th stratum. Whether the stratum is stable is successively determined from the shallow to the deep part of the roof of the roadway according to the principle. If the first stratum is stable, it is unnecessary to calculate the stability of the second to the $n$th strata. This stratum is taken as a reference for designing the support parameters. If the first stratum is unstable, we analyze whether the second stratum overlying the roadway is stable. In this case, instability and collapse can occur in the first stratum because of which it should be regarded as a load and its weight should be included in the calculation. By analogy, for the $x$ th stratum, the load of the underlying unstable stratum is the weight of the first to 


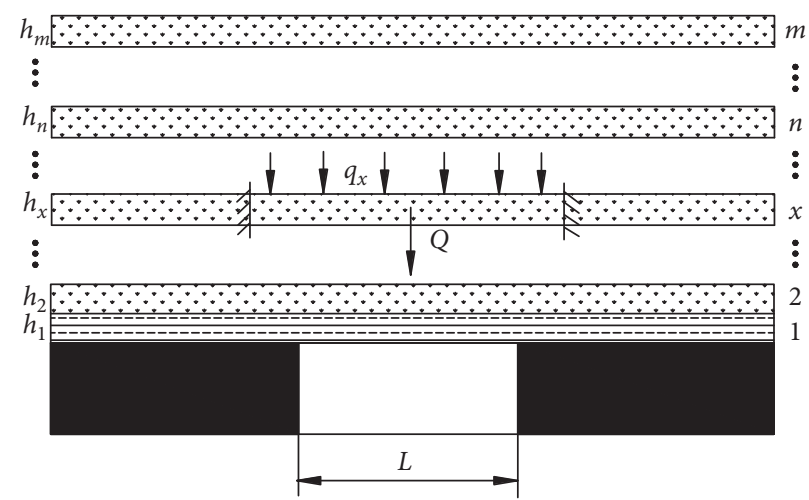

FIGURE 4: Mechanical model of clamped-clamped beams in the roof.

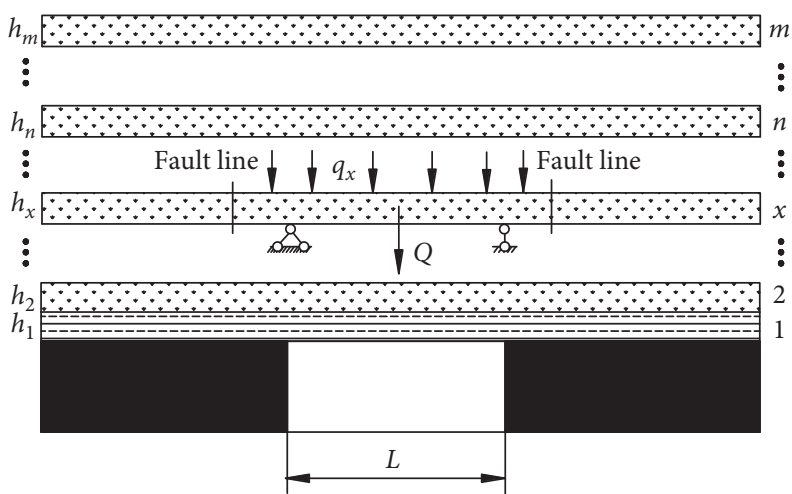

Figure 5: Mechanical model of the lintel structure of the layered roof stratum of the roadway.

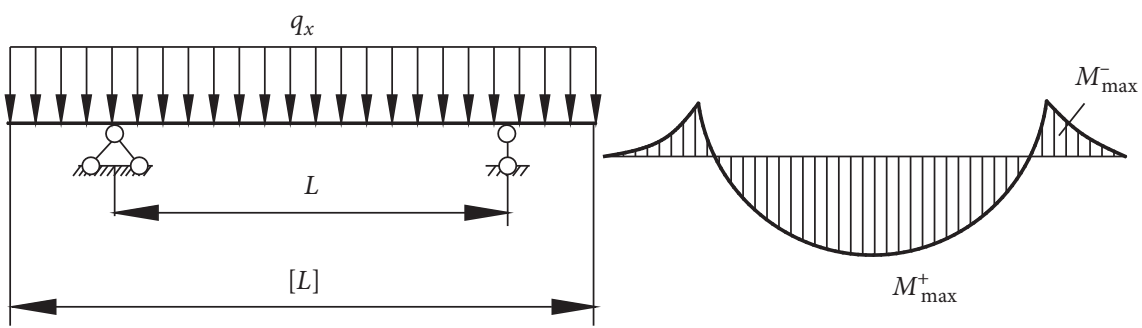

Figure 6: Bending moment.

the $x-1$ th strata. Thus, according to the principle of composite beams, the load of overlying strata formed when the $n$th layer affects the $x$ th layer is as follows:

$$
\left(q_{n}\right)_{x}=\frac{E_{x} h_{x}^{3}\left(\gamma_{x} h_{x}+\gamma_{x+1} h_{x+1}+\cdots+\gamma_{n} h_{n}\right)}{E_{x} h_{x}^{3}+E_{x+1} h_{x+1}^{3}+\cdots+E_{n} h_{n}^{3}}
$$

where $E_{x}, h_{x}$, and $\gamma_{x}$ represent the elastic modulus $(\mathrm{MPa})$, thickness $(\mathrm{m})$, and volume force $\left(\mathrm{N} / \mathrm{m}^{3}\right)$ of the $x$ th stratum, respectively.

The load of the unstable stratum underlying the $x$ th rock beam is expressed as follows:

$$
Q_{x}=\gamma_{1} h_{1}+\gamma_{2} h_{2}+\cdots+\gamma_{x-1} h_{x-1} .
$$

Therefore, the total load imposed on the $x$ th rock beam is the sum of equations (14) and (15):

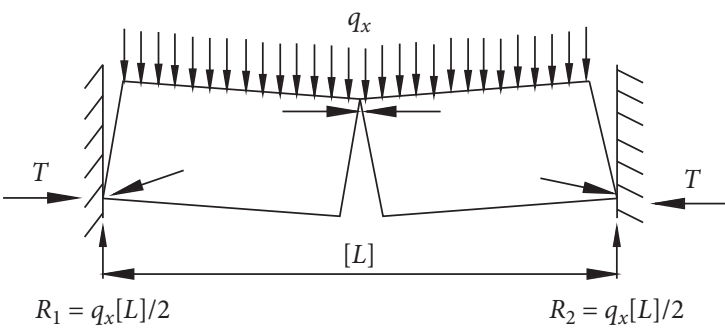

FIGURE 7: An articulated balanced structure of blocks.

$$
q_{x}=\left(q_{n}\right)_{x}+Q_{x}
$$

(2) Method for determining stratum instability in layered roof. Based on the layer thickness $h_{n}$, load $q_{x}$, and strength $\sigma_{t x}$ of the roof strata as well as $f_{c}$, 
$f_{m}, f_{d}$, and $f_{w}$-representing the burial depth, abnormal in situ stress, and integrity-the stability of the $x$ th stratum is determined according to the following criterion:

$$
h_{x} f_{w} \sqrt{\frac{2 \sigma_{t x}}{q_{x} f_{m} f_{d}}}<L .
$$

According to equation (17), the $x$ th stratum is determined to be stable, and the relationship between the maximum normal stress $\sigma_{\max }^{+}$of the lintel structure formed by the $x$ th stratum and the layer strength $\sigma_{t x}$ should continue to be determined. When $\sigma_{\max }^{+}<\sigma_{t x}$, the beam does not break in the middle, and thus, the $x$ th stratum is determined to be stable. If $\sigma_{\max }^{+}>\sigma_{t x}$, the beam is broken in the middle to form the classical articulated structure of blocks. Thus, the stability of the $x$ th stratum should continue to be determined. If this stratum is stable, the $x$ th stratum is determined to be stable. If this stratum is unstable, we need to continue to determine the stability of the $x+1$ th stratum.

Finally, stratum stability is determined layer by layer from the shallow to the deep roof strata of the roadway until the stable stratum is found. This yields the thickness of unstable roof strata, that is, the height of roof caving:

$$
H=\sum_{x-1}^{n=1} h_{n}
$$

\subsection{Roof Caving in Butterfly-Shaped Plastic Zone of Roadway with Fractured Surrounding Rock Mass}

2.3.1. Stress at the Point of Surrounding Rock with a Circular Hole in Inhomogeneous Stress Field in Polar Coordinates. A schematic diagram of a hole in an inhomogeneous stress field is shown in Figure 8. Under the inhomogeneous stress field, according to the theory of elastic mechanics, stress at a point in the rock surrounding the hole in polar coordinates can be obtained by the following formula:

$$
\begin{aligned}
& \sigma_{r}=\frac{\gamma H}{2}\left[(1+\lambda)\left(1-\frac{R_{0}^{2}}{r^{2}}\right)+(1-\lambda)\left(1-4 \frac{R_{0}^{2}}{r^{2}}+3 \frac{R_{0}^{4}}{r^{4}}\right) \cos 2 \theta\right], \\
& \sigma_{\theta}=\frac{\gamma H}{2}\left[(1+\lambda)\left(1+\frac{R_{0}^{2}}{r^{2}}\right)-(1-\lambda)\left(1+3 \frac{R_{0}^{4}}{r^{4}}\right) \cos 2 \theta\right], \\
& \tau_{r \theta}=\frac{\gamma H}{2}\left[(1-\lambda)\left(1+2 \frac{R_{0}^{2}}{r^{2}}-3 \frac{R_{0}^{4}}{r^{4}}\right) \sin 2 \theta\right],
\end{aligned}
$$

where $\sigma_{\theta}, \sigma_{r}$, and $\tau_{r \theta}$ indicate the circumferential stress, radial stress, and shear stress $(\mathrm{MPa})$ at any point, respectively; $\gamma H, \lambda$, and $R_{0}$, respectively, represent the vertical load $(\mathrm{MPa})$ of the roadway, the coefficient of lateral pressure, and the radius $(m)$ of a circular roadway; and $r$ and $\theta$ denote the polar coordinates of any given point.

2.3.2. Calculation of Butterfly-Shaped Plastic Boundary Lines. In polar coordinates, elastic stress at any point in the hole can be substituted into the plastic criterion for calculation to obtain the approximate equation of plastic boundary lines of rock surrounding the hole.

The principal stresses $\sigma_{1}$ and $\sigma_{3}$ under the minimum ultimate strength are used to express the Mohr-Coulomb strength criterion, that is, the limit equilibrium condition:

$$
\sigma_{1}=2 C \frac{\cos \varphi}{1-\sin \varphi}+\frac{1+\sin \varphi}{1-\sin \varphi} \sigma_{3} .
$$

It is rewritten as

$$
\left(\sigma_{1}-\sigma_{3}\right)-\left(\sigma_{1}+\sigma_{3}\right) \sin \varphi=2 C \cos \varphi
$$

The principal stress under plastic conditions can be calculated based on the vertical and horizontal stresses:

$$
\left\{\begin{array}{l}
\sigma_{1}=\frac{\sigma_{r}+\sigma_{\theta}}{2}+\sqrt{\left(\frac{\sigma_{r}-\sigma_{\theta}}{2}\right)^{2}+\left(\tau_{r \theta}\right)^{2}}, \\
\sigma_{3}=\frac{\sigma_{r}+\sigma_{\theta}}{2}-\sqrt{\left(\frac{\sigma_{r}-\sigma_{\theta}}{2}\right)^{2}+\left(\tau_{r \theta}\right)^{2}} .
\end{array}\right.
$$

By substituting the calculated principal stress into equation (21), the equation of plastic conditions of the rock surrounding the roadway can be obtained:

$$
\begin{aligned}
& \left(\frac{\sigma_{r}-\sigma_{\theta}}{2}\right)^{2}+\left(\tau_{r \theta}\right)^{2}-\left(\frac{\sigma_{r}+\sigma_{\theta}}{2}\right)^{2} \sin ^{2} \varphi \\
& \quad-\left(\sigma_{r}+\sigma_{\theta}\right) \sin \varphi \cos \varphi C-C^{2} \cos ^{2} \varphi=0 .
\end{aligned}
$$

By substituting elastic stress at a point in the hole under polar coordinates in equations (19) into (23), the approximate equation of plastic boundary lines of the surrounding rock in an inhomogeneous stress field under polar coordinates can be obtained: 


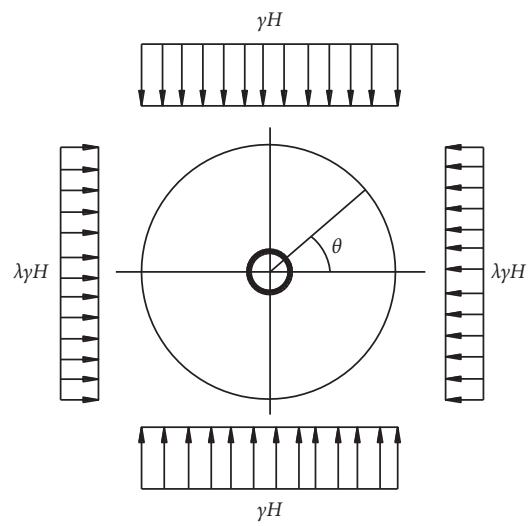

FIGURE 8: Stress around a hole under inhomogeneous stress conditions.

$$
\begin{aligned}
& 9(1-\lambda)^{2} \cdot\left(\frac{R_{0}}{r}\right)^{8}-\left[12\left(1-\lambda^{2}\right)+6\left(1-\lambda^{2}\right) \cos 2 \theta\right] \cdot\left(\frac{R_{0}}{r}\right)^{6} \\
& +2(1-\lambda)^{2}\left[\cos ^{2} 2 \theta\left(5-2 \sin ^{2} \varphi\right)-\sin ^{2} 2 \theta\right]+(1+\lambda)^{2}+4\left(1-\lambda^{2}\right) \cos 2 \theta \cdot\left(\frac{R_{0}}{r}\right)^{4} \\
& -\left[4(1-\lambda)^{2} \cos 4 \theta+2(1-\lambda)^{2} \cos 2 \theta\left(1-2 \sin ^{2} \varphi\right)-\frac{4}{\gamma H}(1-\lambda) \cos 2 \theta \sin 2 \varphi C\right] \\
& \cdot\left(\frac{R_{0}}{r}\right)^{2}(1-\lambda)^{2}-\sin ^{2} \varphi\left(1+\lambda+\frac{2 C}{\gamma H} \frac{\cos \varphi}{\sin \varphi}\right)^{2}=0 .
\end{aligned}
$$

The above shows that the approximate equation of butterfly-shaped plastic boundary lines of rock surrounding the hole is affected by various factors, mainly the coefficient $\lambda$ of lateral pressure, cohesion C, angle $\varphi$ of internal friction of the surrounding rock, burial depth $\mathrm{H}$ of the hole, unit weight $\gamma$ of the rock surrounding the hole, and radius $R_{0}$ of the hole. Given the other factors, the depth $r$ of the butterfly-shaped plastic zone under different values of $\theta$ of the roof of the roadway can be obtained by equation (24). This can be used to calculate the height at which the roof is at risk of caving in the butterfly-shaped zone, as shown in Figure 9:

$$
h=\operatorname{Max}_{\theta \in[0, \pi]}(r \times \sin \theta)-R_{0} .
$$

2.4. Mechanical Analysis of Leakage of Roof with Loose Surrounding Rock Mass. Protodyakonov theory is generally used to examine roof leakage in a roadway with loose surrounding rock mass. It claims that, after roadway excavation, stress in the surrounding rock is redistributed to generate secondary stress that damages it. The primary result of roadway failure is the caving of loose roadway roof rock and the formation of an arch in the crushed zone, as shown in Figure 10.

From the perspective of loose and fractured rock, the height of the caving arch is

$$
h_{0}=\frac{b m}{f}=\frac{\left[a+h t g\left(45^{\circ}-(\varphi / 2)\right)\right] m}{f},
$$

where $a, h, \varphi, f$, and $m$ represent the radius of the roadway, its height, the angle of internal friction, the Protodyakonov coefficient, and the safety factor, respectively.

The factors affecting the critical stable height of the roof of the roadway with loose surrounding rock mass include the radius of the roadway, its height, angle of internal friction of the surrounding rock, the Protodyakonov coefficient, and the safety factor.

\section{Indicator System for Grading Risk of Caving of Roof of Coal Roadway}

\subsection{Design Principle for Grading Risk of Caving of Roof}

(1) Based on the results of grading the risk of the caving of the roof of the roadway in the coal seam, the prevalent support modes and parameters for the excavated roadway were calculated to find areas at high risk of caving in a timely manner and take reasonable and effective preventative measures.

(2) For the tunnel to be excavated, reasonable support modes and parameters were designed according to a zoning map of risk grades of caving of the roof in the coal seam. This was used to develop a targeted support design that reduces support costs and eliminates the risk of caving of the roof.

3.2. Indicator System for Grading Risk of Roof Caving. Many factors influence the stability of the roof of the roadway, but it is impossible to consider each to classify the 


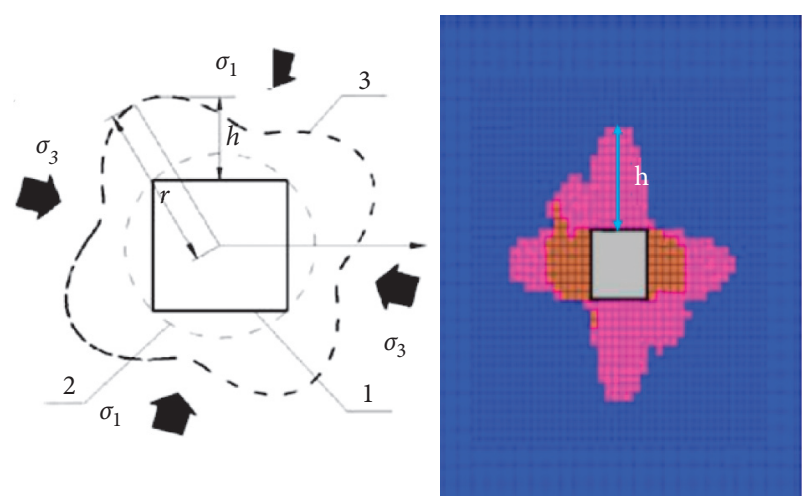

FIGURE 9: Roof caving in the butterfly-shaped plastic zone of the roadway with fractured surrounding rock mass.

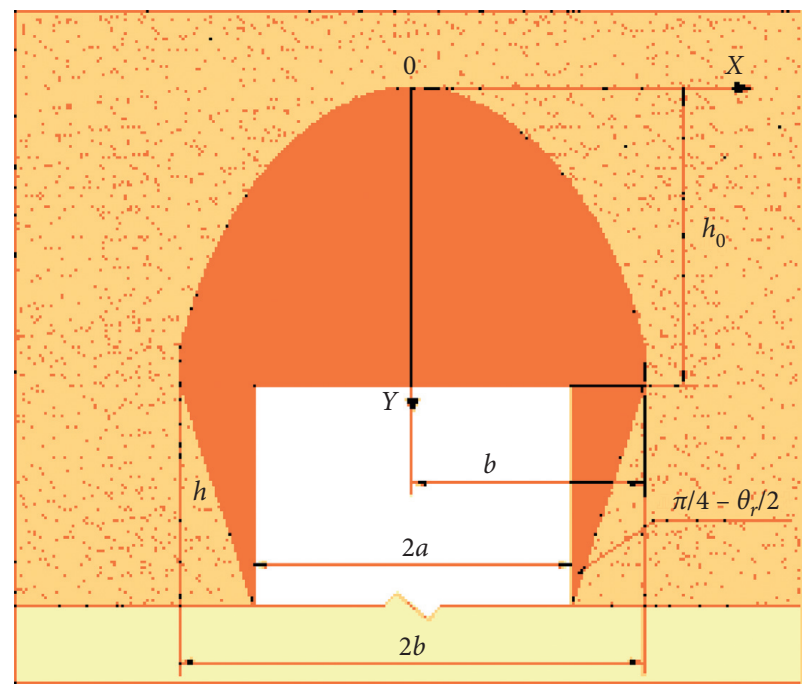

FIGURE 10: Roof leakage of a roadway with loose surrounding rock.

risk grading. According to equation (6), the critical height $H_{1}$ of local blocks of the roof with fractured surrounding rock mass is related to the length $l$ of the free face, dip angle $\alpha$ of the structural plane of the block, frictional angle $\varphi$, coefficient $\lambda$ of lateral pressure, and buried depth $h$ of the roadway. According to equation (18), the critical stable height $\mathrm{H}_{2}$ of the composite roof of the roadway with weakly bonded and layered surrounding rock mass is correlated with the abnormal in situ stress, span of the roadway, uniaxial tensile strength, burial depth, uniaxial compressive strength, the imposed load on the strata, their limit span, integrity coefficient, angle of rotation of the rock blocks, and roof subsidence. Equation (25) shows that the critical stable height $\mathrm{H}_{3}$ of the roof in the butterfly-shaped plastic zone is correlated with the coefficient $\lambda$ of lateral pressure, angle $\varphi$ of internal friction, cohesion $\mathrm{C}$, burial depth $m$ of the roadway, and its radius $R_{0}$. Based on equation (26), the critical stable height $H_{4}$ of the roof of the roadway with loose surrounding rock mass is correlated with the radius and height of the roadway, angle of internal friction of the surrounding rock, Protodyakonov coefficient, and safety factor. These factors are shown in Figure 11.

Too many factors affect the stability of the roof strata of the roadway to describe quantitatively as indicators for classification or grading. Moreover, the indicators for classification cannot clearly express the basic characteristics of the surrounding rock mass. As shown in Figure 11, these factors directly or indirectly affect the height of caving of the roof, which is used to determine the design of the support parameters with anchor bolts and cables. The larger the failure depth of the roadway roof is, the higher the roof caves, and the larger the weight is because of which the longer are the anchor bolts and cables needed. The risk grading of roof caving should be in accordance with the required lengths of conventional anchor bolts, connected long bolts, or short anchor cables as well as long anchor cables arranged in undamaged strata. The available anchor bolts are generally $1.6 \sim 2.5 \mathrm{~m}$ long, whereas some new ultralong bolts or extendable bolts [33-39] can be as long as $4 \sim 7.5 \mathrm{~m}$. Short cables with lengths of $3 \sim 4 \mathrm{~m}$ are used in some mining areas, while $10 \sim 14 \mathrm{~m}$ or longer cables are used in others. In general, anchor cables with a length of $5 \sim 10 \mathrm{~m}$ are used. The characteristics and grading of roof stability are listed in Table 1.

For a grade I roof, the lowest height of the roof caving and the range to be anchored is within the reach of conventional anchor bolts. The maximum height of caving is set to $1.5 \mathrm{~m}$. The weight of the strata that need to be controlled is small for such a roof and can be used as a bearing layer. Caving accidents at great heights generally do not occur. In designing the support parameters, it is necessary to ensure that rock in the bearing layer does not cave locally. Therefore, such a roof has the lowest risk grade of caving, which is indicated by green when drawing the grading map of risks.

Compared with a grade I roof, a grade II roof has a greater height of caving of the roof that exceeds the range of conventional anchor bolts. However, when using connected long bolts and short anchor cables, this height is within the range of anchorage. When such roofs are set to have a maximum caving height of $3.5 \mathrm{~m}$, they can still be used as the bearing layer. When designing support parameters, caving accident at great heights does not occur, even not anchor cables are not used, so long as the forms of conventional anchor bolts and connected long bolts as well as the lengths of the anchor ends are reasonable. The grade II roof has the moderate risk of caving, which is represented by yellow in the grading map of risks.

The caving height of a grade III roof is beyond the reaches of conventional anchor bolts, connected long bolts, and short anchor cables. Such roofs need to be supported by long anchor cables. The maximum caving height of the roof is set to $5.5 \mathrm{~m}$. Due to the height of such roofs and wide range of failure of the strata, caving accidents easily occur underground. Therefore, in designing the support parameters, such a roof should be supported by conventional anchor bolts combined with long anchor cables. If necessary, layered support should be used; that is, the conventional anchor bolts can be used to form the primary anchorage and bearing structure to support the surrounding rock, which can easily fracture in a shallow roof. Connected long bolts or short anchor cables should control stratum separation in the middle and lower roof and coordinate in support with the 


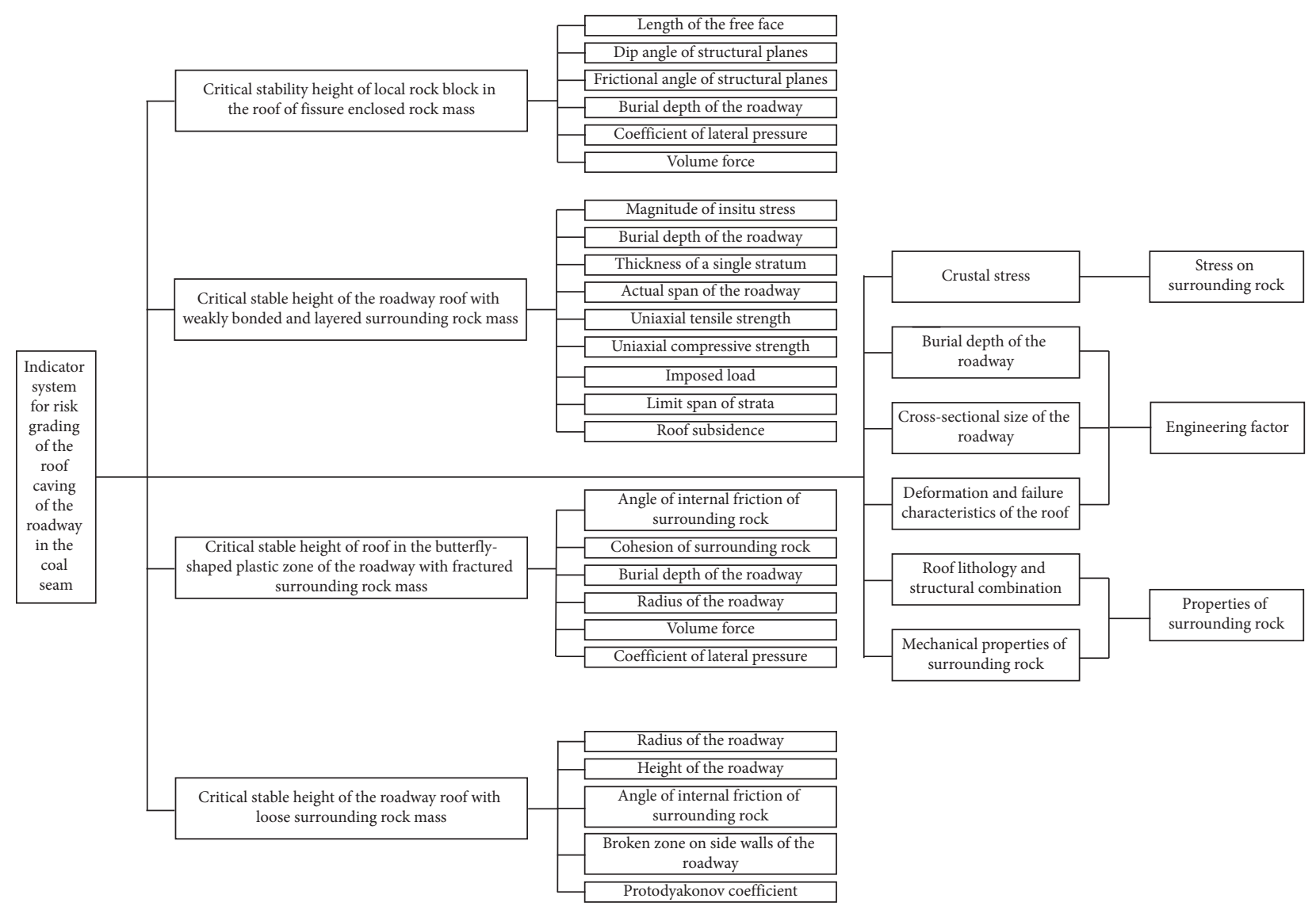

FIGURE 11: Indicator system for grading risk of the roof of the roadway in the coal seam.

TABLE 1: Grading and characteristics of roof stability.

\begin{tabular}{|c|c|c|c|}
\hline Grade & $\begin{array}{l}\text { Height of fractured } \\
\text { roof }\end{array}$ & & Difficulty in controlling roof caving \\
\hline I & $\leq 1.5 \mathrm{~m}$ & Easy & $\begin{array}{l}\text { Under general conditions, the support requirements can be met by using conventional } \\
\text { anchor bolts alone }\end{array}$ \\
\hline II & $\leq 3.5 \mathrm{~m}$ & Difficult & $\begin{array}{l}\text { Use of conventional anchor bolts alone does not work, and they need to be combined with } \\
\text { anchor bolts longer than } 4 \mathrm{~m} \text { or anchor cables to strengthen support }\end{array}$ \\
\hline III & $\leq 5.5 \mathrm{~m}$ & More difficult & $\begin{array}{l}\text { Use of conventional anchor bolts alone does not work, and they need to be combined with } \\
\text { anchor cables longer than } 6 \mathrm{~m} \text { to strengthen support; anchor cables are locally broken }\end{array}$ \\
\hline IV & Undetermined & $\begin{array}{l}\text { Extremely } \\
\text { difficult }\end{array}$ & $\begin{array}{l}\text { When combining anchor bolts with cables for supporting the roof, the probability of } \\
\text { breakage is so high that it is very difficult to prevent the roof from caving }\end{array}$ \\
\hline
\end{tabular}

conventional anchor bolts to form a secondary anchorage and bearing structure. Moreover, anchor cables are used to overhang and anchor the formed secondary anchorage and bearing body to stable strata, which form a layered stereostructure with combined anchoring effects for a certain thickness and bearing strength. Timely and regular monitoring should be conducted during roadway tunneling. The grade III roof poses a high risk of roof caving and is indicated by carmine in the grading map of risks.

The grade IV roof has the greatest caving height, exceeding the range that can be anchored by conventional anchor cables.
The maximum height of caving is undetermined and sometimes exceeds $8 \sim 10 \mathrm{~m}$. Owing to the large failure range, caving height, serious consequences, and high degree of hazard, such a roof can easily cave and trigger caving accidents in adjacent roadways. Furthermore, such accidents are difficult to control. Therefore, observation and monitoring should be strengthened along with providing support, such as by increasing the density, diameter, and length of the anchor cables and erecting steel sheds, to minimize the risk of caving. The grade IV roof has the highest risk grade of caving and is represented in red in the grading map of risks. 


\section{Software for Risk Grading System for Caving of Roof}

\subsection{Method to Predict the Height of Roof Caving}

4.1.1. Introduction to Prediction Methods. There are $i$ types of cavings of the roof of the roadway at the $k$ th coordinate point of the mine $(i=1,2,3,4) ; p_{k}(i)$ represents the empirical probability of the $i$ th type of roof caving at the $k$ th coordinate point, and $\sum_{i=1}^{4} p_{k}(i)=1,0 \leq p_{k}(i) \leq 1(k=$ $1,2, \ldots, n)$

$h_{k}(i)$ indicates the predicted value of the height of the $i$ th type of caving at the $k$ th coordinate point of the mine, where $i=1,2,3,4$ and $k=1,2, \ldots, n$.

$F_{k}=\left(f_{i j}\right)(i=1,2,3,4 ; i=1,2,3,4 ; k=1,2, \ldots, n)$ denotes the fuzzy complementary judgement matrix generated by $p$ at the $k$ th coordinate point of the mine, and $r_{k}(i)(i=$ $1,2,3,4 ; i=1,2,3,4 ; k=1,2, \ldots, n)$ indicates the sum of the $i$ th row in the fuzzy judgement matrix $F_{k}$ at the $k$ th coordinate point of the mine.

$R_{k}=\left(r_{i j}\right)$ is the fuzzy judgement matrix with consistency constructed by row sum $r$ at the $k$ th coordinate point of the mine, where $i=1,2,3,4, \quad j=1,2,3,4$ and $k=1,2, \ldots, n$.

$w_{k}(i)$ represents the weighted average coefficient corresponding to the $i$ th type of caving of the roadway at the $k$ th coordinate point of the mine, where $i=1,2,3,4$ and $\sum_{i=1}^{4} w_{k}(i)=1,0 \leq w_{k}(i) \leq 1(k=1,2, \ldots, n)$.

$H_{k}$ denotes the predicted value of the height of the caving of the roof of the roadway at the $k$ th coordinate point of the mine $\left(k=1,2, \ldots, n, H_{k}=\sum_{i=1}^{4} w_{k}(i) h_{k}(i)=1,0\right.$ $\left.\leq w_{k}(i) \leq 1\right)$.

\subsubsection{Calculation of Indicators of Fuzzy Variable Weight}

(1) It is assumed that the empirical probability of the $i$ th type of caving of the roof of the roadway at the $k$ th coordinate point of the mine is $P_{k}(i)(i=1,2,3,4)$ and $\sum_{i=1}^{4} p_{k}(i)=1,0 \leq p_{k}(i) \leq 1(k=1,2, \ldots, n)$ If the $i$ th type of caving is not likely to occur, that is, its empirical probability is zero, it is not considered when forming the fuzzy judgement matrix.

(2) We establish the fuzzy judgement matrix:

$$
F=\left(f_{i j}\right)_{4 \times 4}=\left(\begin{array}{llll}
f_{11} & f_{12} & f_{13} & f_{14} \\
f_{21} & f_{22} & f_{23} & f_{24} \\
f_{31} & f_{32} & f_{33} & f_{34} \\
f_{41} & f_{42} & f_{43} & f_{44}
\end{array}\right), \quad \text { where } f_{i j}= \begin{cases}0.5, & P_{i}=P_{j}, \\
\frac{P_{i}}{P_{i}+P_{j},} & P_{i} \neq P_{j} .\end{cases}
$$

(3) To determine the weighted average coefficient corresponding to the $i$ th type of caving at the $k$ th coordinate point of the mine, the fuzzy matrix with consistency $R=\left(r_{i j}\right)_{4 \times 4}$, a matrix that meets the following relationship, is constructed:

(i) $0 \leq r_{i j} \leq 1(i, j=1,2,3,4)$.

(ii) $r_{i j}+r_{j i}=1(i, j=1,2,3,4)$.

(iii) $\forall i, j, r_{i j}=w_{k}(i)$ $-w_{k}(j)+0.5(i, j=1,2,3,4 ; k=1,2, \ldots, n)$.
The row sum $r_{i}=\sum j=1^{4} f_{i j}$ is calculated, and the fuzzy judgement matrix $F=\left(f_{i j}\right)_{4 \times 4}$ is transformed into the fuzzy judgement matrix with consistency $R=\left(r_{i j}\right)_{4 \times 4}$ by using the formula $r_{i j}=(1 / 2) \times\left(\left(r_{i}-\right.\right.$ $\left.\left.r_{j} / n\right)+1\right)$.

(4) If $R$ is the fuzzy judgement matrix with consistency, the weighted average coefficient can be calculated by $W_{k}=(1 / k)\left(\sum_{j=1}^{k} r_{i j}+1-(1 / k)\right)$. If $\sum_{j=1}^{k} r_{i j} \leq(1 / k)$ -1 , this needs to be modified until $W_{k}>0$. The vector of the weighted average coefficient is as follows:

$$
W_{k}=\left(w_{k}(1), w_{k}(2), w_{k}(3), w_{k}(4)\right)^{T}=\frac{1}{4}\left(\left(\sum_{j=1}^{4} r_{1 j}+1-\frac{1}{4}\right),\left(\sum_{j=1}^{4} r_{2 j}+1-\frac{1}{4}\right),\left(\sum_{j=1}^{4} r_{3 j}+1-\frac{1}{4}\right),\left(\sum_{j=1}^{4} r_{4 j}+1-\frac{1}{4}\right)\right)^{T} \text {. }
$$


4.1.3. Predicted Value of Height of Roof Caving of the Roadway. After calculating $W_{k}$, the predicted value of the height of caving of the roof of the roadway at the $k$ th coordinate point of the mine can be obtained by $h_{k}(i)$, which is calculated as follows:

$$
H_{k}=\sum_{j=1}^{4} w_{k}(i) h_{k}(i)=1, \quad 0 \leq w_{k}(i) \leq 1, k=1,2, \ldots, n .
$$

\subsection{Software Design of Risk Grading System}

(1) Login interface. Once it opened, the homepage of the program for the risk grading system appears, as shown in Figure 12. It has "login" and "logout" buttons. By clicking the former, the user can access the input module of the index samples, operation module, and the display module for the calculations and results.

(2) System interface. Once the user has logged into the system interface, the first interface is as shown in Figure 13. The items [local block falling], [composite roof caving], [caving in butterfly-shaped plastic zone], [loose roof leakage], and [grading results] are listed in the toolbar. For each module, according to the parameters entered by the user into different modules of the calculation, the calculations are made by using programmed formulae and algorithms. When calculating the first module, the name of the given mine, serial number of a single borehole, and its coordinates ( $\mathrm{X}$ and $\mathrm{Y}$ ) on the mining plan need to be first input.

This information interface can be accessed by clicking the button "local block falling" on the system interface. For calculation of the local block falling module, it is necessary to enter parameters, including the length of the free faces, coefficient of lateral pressure, dip angle of the structural planes, and their frictional angles. By clicking the button "Calculate," the height $\mathrm{H} 1$ of the caving of the roof of local blocks of the roadway roof can be obtained and can be saved by clicking the button "Save." If a mistake is made in the input process, the button "Delete" can be clicked to reinput the parameters.

For calculations of composite roof caving module, the parameters are successively entered for each ground borehole and peephole drilled from bottom to top in the corresponding roof of the roadway. They include the thickness of a single stratum, lithology, lithology code, compressive strength, tensile strength, elastic modulus, volume force, span of the roadway, its burial depth, and the measured in situ stress. By clicking the button "Calculate," the effective thickness of the strata, in situ stress, burial depth of the roadway, and limit span of each stratum can be obtained. Finally, the caving height $\mathrm{H} 2$ of the composite layered roof of the roadway can be obtained and saved by clicking "Save."

In calculations in case of caving in the butterfly-shaped plastic zone, the angle of internal friction of the surrounding rock, its cohesion, burial depth of the roadway, its radius, volume force, coefficient of lateral pressure, and angle of butterfly wings need to be entered. By clicking "Calculate," the height $\mathrm{H} 3$ of the caving in the zone can be obtained and saved by clicking "Save."

For calculations of the module for loose roof leakage, the input parameters are the angle of internal friction of the surrounding rock, height of the roadway, Protodyakonov coefficient, radius of the roadway, and safety factor. "Calculate" can then be clicked to obtain the height $\mathrm{H} 4$ of the loose roof caving and saved by clicking "Save."

Finally, by clicking "Generating document," all the above results can be saved in text format (.txt). The user then clicks "Close" to proceed to enter information for the next borehole.

\section{An Engineering Example of Risk Grading and Control of Caving Roof of Coal Roadway}

5.1. Risk Grading of Caving Roof in Zhaogu Coal Mine No. 2. We used coal seam No. III of Zhaogu Coal Mine No. 2 in Jiaozuo, Henan Province, China, as an example of determining the graded risks of caving of a layered roof of the roadway. Due to limitations in space, the parameter acquisition process and test results are not discussed in detail. The results were obtained by means of field investigation and measurements of the force of the anchor bolts (cables), broken zone test, and physical and mechanical tests. By entering the parameters of the stratum obtained from ground boreholes and peepholes in the roof into the risk grading system developed here, the height of the caving of the roof was calculated. Based on this, the risk grades of caving were determined. The coordinates of a single borehole were determined and matched to the relevant drawings, such as the mining plan of the coal seam. The zoning map of the risk grades of the roof caving in the entire mine was obtained by using SURFER software to guide production, as shown in Figure 12.

The entire well field was at high risk of the roof caving. The well field was dominated by roofs of risk grade III, covering an area twice that of that covered by roofs at risk grade II. As the well field extended to the west panel, the mining depth gradually increased and the area of roofs with risks in grade III gradually increased.

Some sections in the well field contained roofs with risk grade IV. The area of intersection of faults with structures and the boundary between roofs of grades III and IV mostly contained roofs with a high caving risk and needed to be monitored intensively during roadway construction.

For roofs with risk grade III, reasonably designing the support parameters can help prevent caving accidents. For roofs with risk grade IV, even if the intensity and density of support are increased, there is still the possibility of local caving accidents. Therefore, it is necessary to strengthen monitoring and take reasonable and effective measures in time to avoid injuries.

5.2. Correction of Support Parameters. According to the zoning results of risk grades of caving in coal seam No. III in Zhaogu Coal Mine No. 2, underground application and tests 


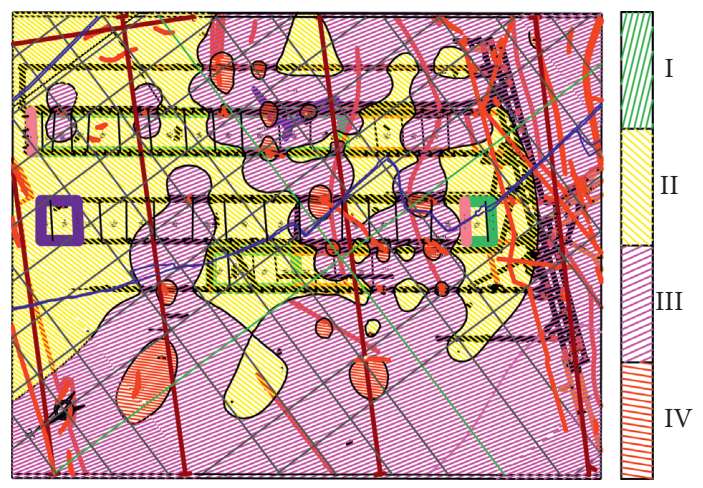

Figure 12: Zoning map of risk grades of roof caving in coal seam No. III.

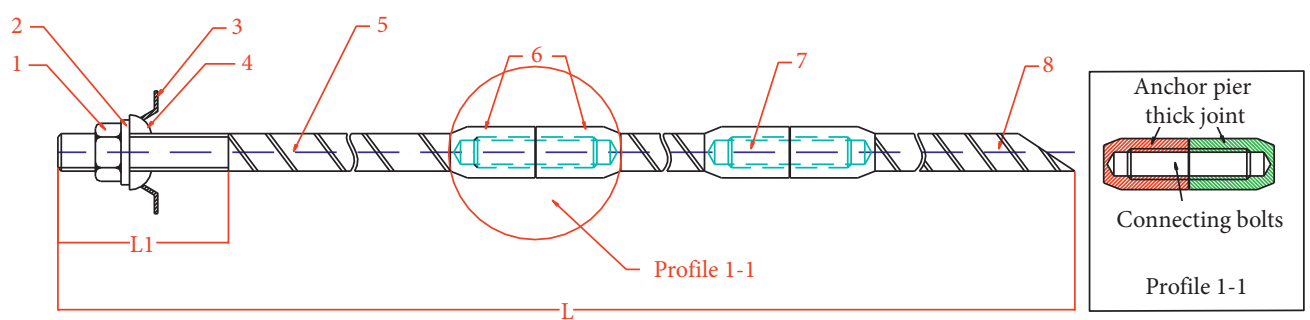

Figure 13: Connected long anchor bolt and accessories. 1, nut; 2, plastic washer; 3, tray; 4, ball seat; 5, bolt; 6, upset connector; 7, connecting bolt; 8 , anchor head.

were carried out in the intake airway of working face 11030 of the mine. Targeted support designs were implemented in the areas with different risk grades of caving using long anchor bolts. The long anchor bolts consisted of a connector of anchor bolts, metal bolts, a screw nut at the anchor end, and a connecting bolt, as shown in Figures 13 and 14 .

The primary support design of the intake airway of working face 11030 is shown in Figure 15. According to Figure 12, within $0 \sim 250 \mathrm{~m}$ in the intake airway, the risks of caving were graded as II, while those in the range of 680 780 m were mostly grade as III. Therefore, roof support for grade II roofs was designed in the range $180 \sim 210 \mathrm{~m}$. Conventional anchor bolts combined with long anchor bolts [33-39] were used as the main support without using anchor cables. The support design is illustrated in Figure 16.

Within $680 \sim 780 \mathrm{~m}$ of the working face, the support design for grade III roofs was used. According to geological data, this section was located adjacent to faults F107, F109, and F111. To ensure safety, the layered support design was used. The primary anchorage and bearing structure were used in the easily fractured surrounding rock in the shallow roof using conventional anchor bolts; connected long bolts were used to control stratum separation in the middle and lower parts of the roof and formed a secondary anchorage and bearing structure through coordinated support with the conventional anchor bolts. Moreover, by using the anchor cables, the secondary anchorage and bearing body overhung and were anchored in the stable strata. This formed a layered stereostructure with the combined effects of anchoring of a certain thickness and bearing strength [40-44]. The support design is shown in Figure 17.
After correcting the support parameters, the measuring points were arranged in areas with roofs in risk grades II and III for measurement and monitoring. For the area with roofs in grade II, the strengthened monitoring was intended to identify the deep failure of roof strata and prevent the roof from worsening to grade III. The monitoring data are analyzed below.

5.3. Analysis of Observation of Mine Pressure. A monitoring system for deep displacement at multiple base points was set in the intake airway of working face 11030 to monitor the deep deformation of the surrounding rock. In contrast to ordinary displacement meters at deep base points, highly sensitive equipment can transform the displacement signals into electrical signals for analysis with an accuracy of $0.2 \mathrm{~mm}$. In other words, small displacements in strata could be recorded and could accurately reflect the laws of deformation and failure of the surrounding rock, as shown in Figure 18.

Figure 19 shows the results of monitoring of displacement at deep base points within 46 days in the intake airway of working face 11030. When installing the displacement monitoring instrument at multiple base points, four points were set at 1, 2.5, 4, and $8 \mathrm{~m}$ above the roof. In sections of the roof with risk grades II and III in the roadway, several monitoring stations were set. The measuring points in two monitoring stations with prominent trends of changes in displacement are presented. Figures 19(a) and 19(b), respectively, show displacements at monitoring stations in the roofs with risk grades II and III. 


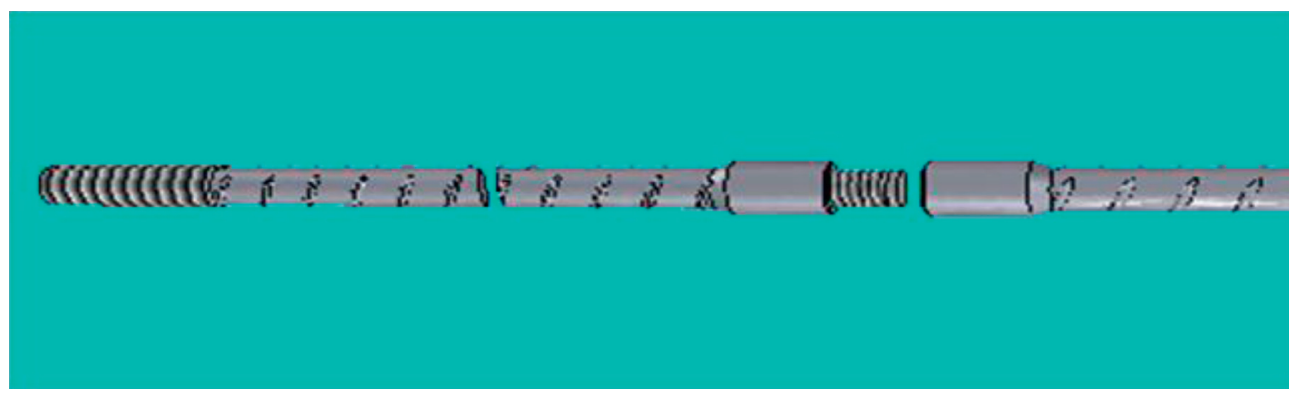

FIGURE 14: Schematic diagram of the long anchor bolt.

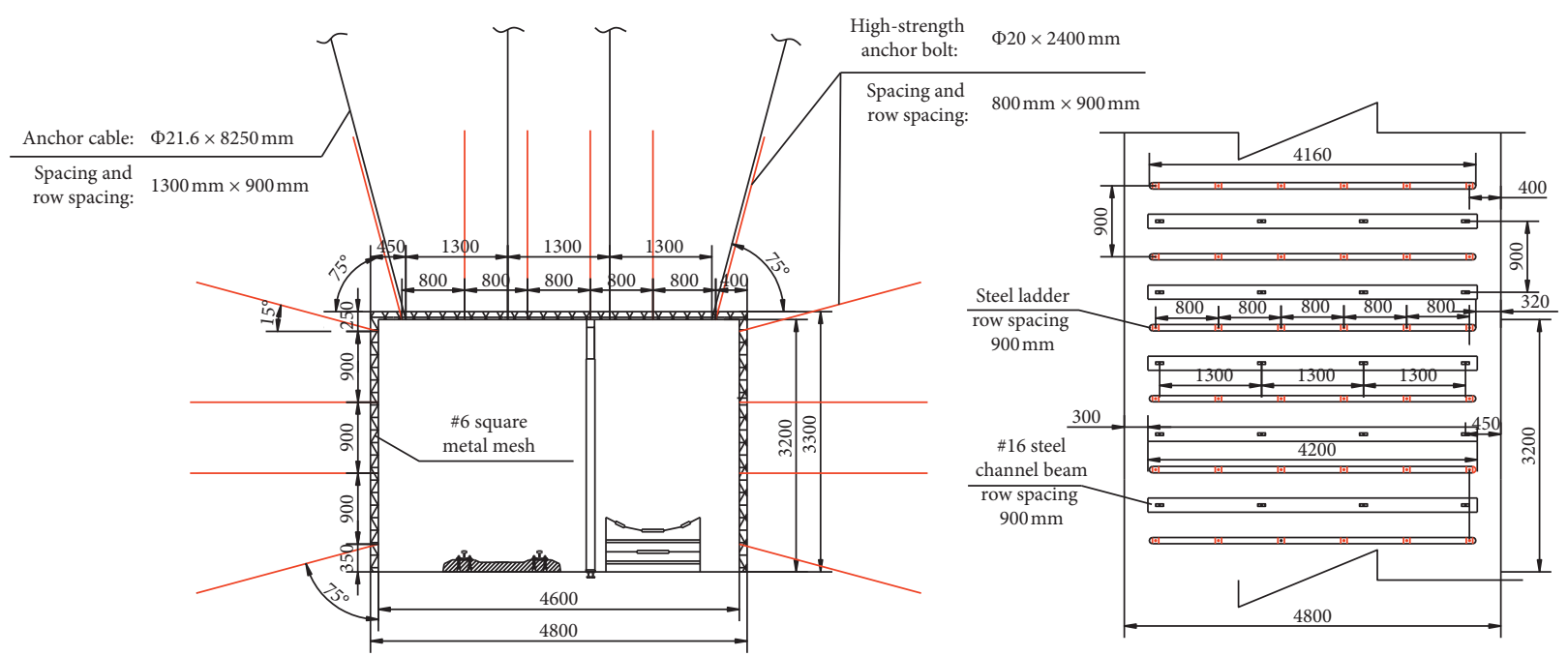

FIGURE 15: Cross section of the roadway and support design of intake airway of working face 11030.

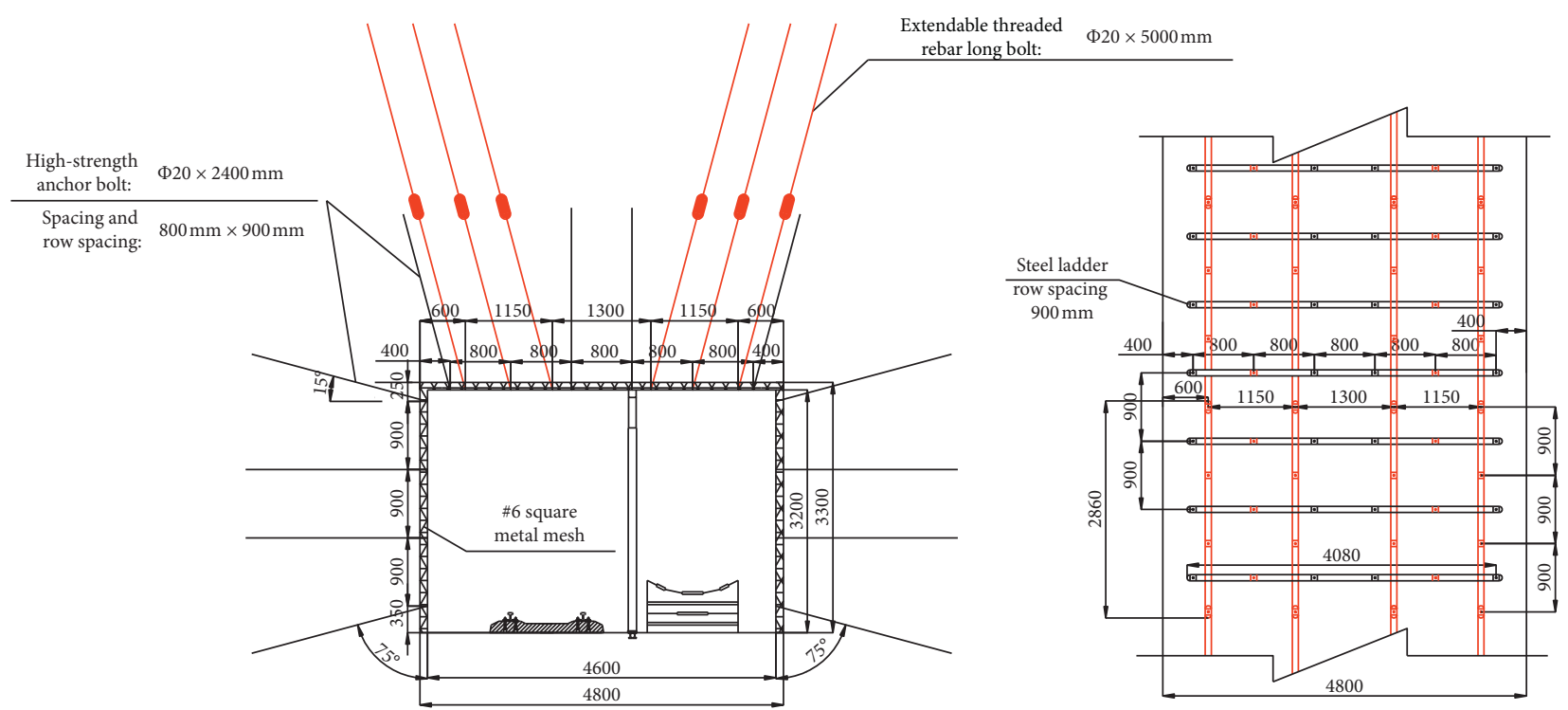

FIGURE 16: Support design for roof with grade II risk in the intake airway of working face 11030 of the mine.

A comparison of the two displacement curves in Figure 19 shows that the roof with risks in grade II deformed quickly in the first 10 days of the monitoring period, and the overall displacement was $67 \mathrm{~mm}$. The overall displacement was gentle later in the monitoring period. As the change in displacement stabilized, the overall displacement was $102 \mathrm{~mm}$, mainly in $0 \sim 1 \mathrm{~m}$ in the shallow part of the roof, while the displacement at other 


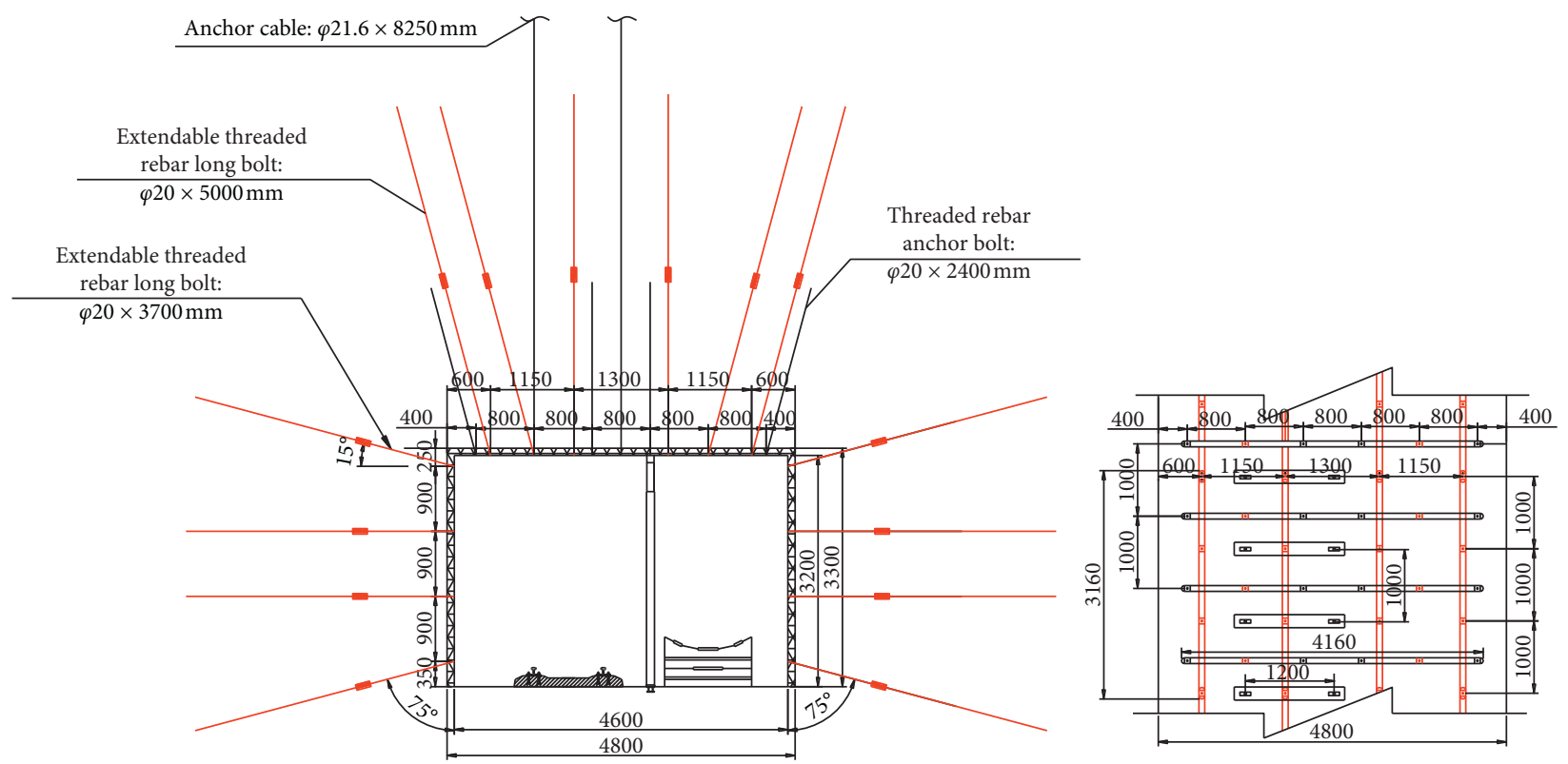

FIGURE 17: Support design for grade III roof in the intake airway of working face 11030.

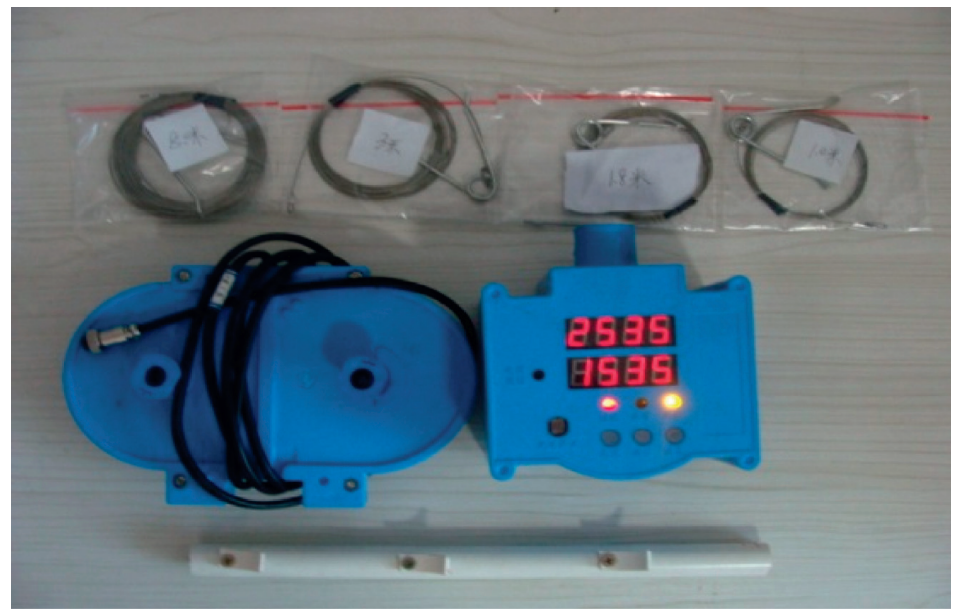

(a)

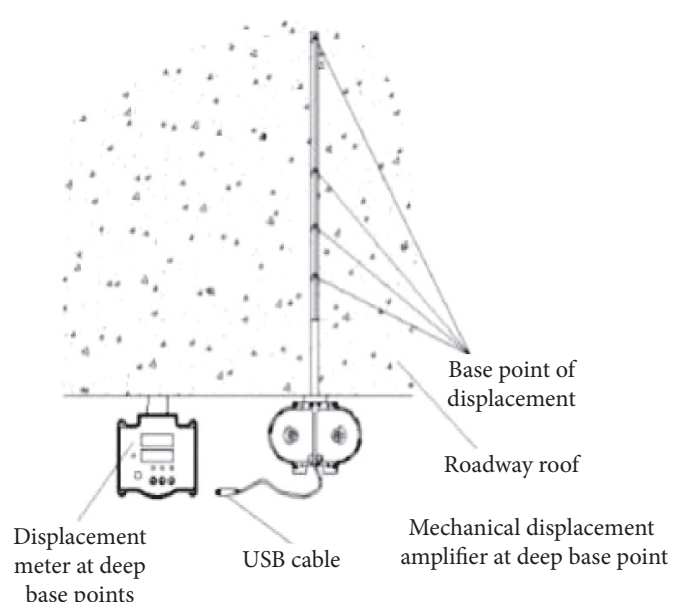

(b)

Figure 18: A monitoring system for deep displacement at multiple base points.

base points was moderate. In the first 20 days of the monitoring period, the roofs with risk grade III deformed quickly and considerably, with an overall displacement of $168 \mathrm{~mm}$. By the $34^{\text {th }}$ day, the change in displacement had stabilized. The maximum displacement in the deep part of the roof was $213 \mathrm{~mm}$, and nearly $80 \%$ of it occurred in the ranges of $0 \sim 1 \mathrm{~m}$ and $2.5 \sim 4 \mathrm{~m}$ in the shallow part of the roof. 


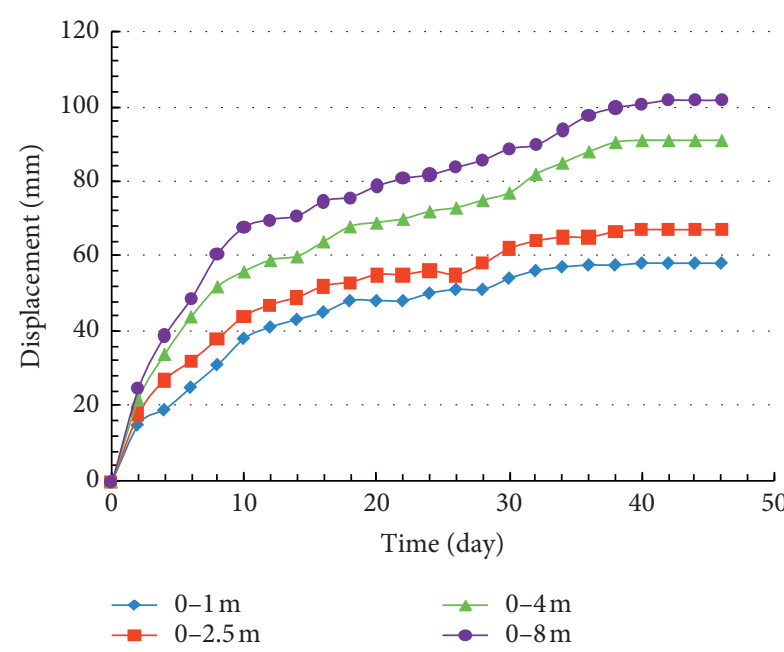

(a)

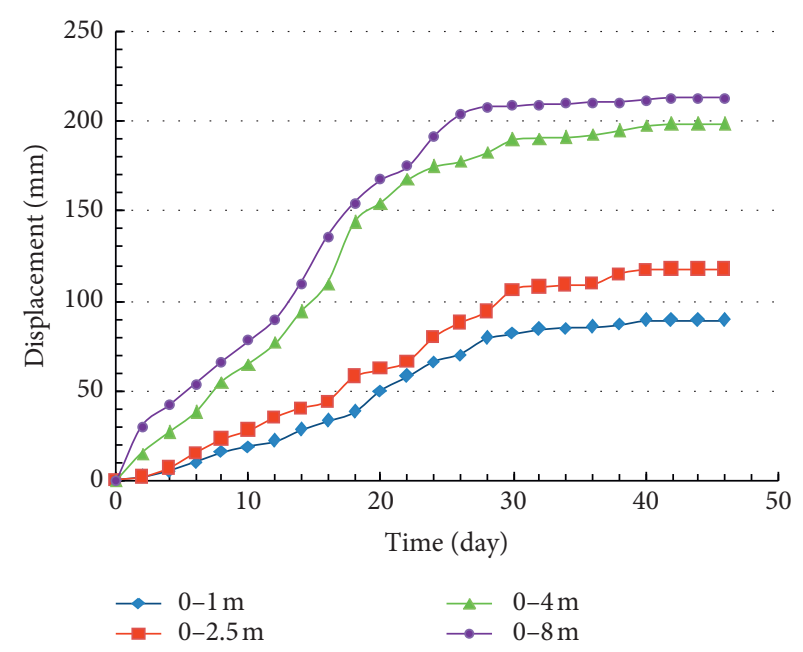

(b)

FIGURE 19: Displacement curves of roof with risks of caving of grades II and III in the intake airway in working face 11030: (a) grade II; (b) grade III.

\section{Conclusions}

In light of the problem of caving roofs in different parts of the same roadway, this study classified and illustrated the mechanical characteristics of local instability of the roof based on differences in rock mass media and types of accidents. Moreover, the factors influencing the quantitative relationship between the failure height of the roof and the environment were ascertained, and an indicator system for grading the risk of caving of roofs of roadways of coal mines was established. The risk grading method can predict the height of caving of the roof in the coal seam through fuzzy variable weighting analysis. We also developed a software for the risk grading system. The main conclusions are as follows.

Based on the difference in rock mass media and types of accidents of the roof of the roadway, the mechanical characteristics of falling, caving, and leakage of local instability were classified, and factors influencing the relationship between the failure height of the roadway roof and the environment were obtained.

By combining the above with interpolation and drawing functions of the SURFER software, a zoning map for risk grades of caving of the roof of the roadway in coal seam No. III of Zhaogu Coal Mine No. 2 was obtained.

The well field was found to have a high overall risk of the roof caving and was dominated by areas in risk grade III. The area of intersection of faults and structures and the boundary between roofs in grades III and IV were mostly in high risk and needed to be monitored during roadway construction.

A targeted support design test was conducted in areas with different risk grades of caving in the same intake airway of working face 11030 of the mine. The observations showed that the proposed risk grading technology conformed to the safety practices of underground mining. The stability of the roadway during service was consistent with the risk grades determined by the software.

\section{Data Availability}

The data used to support the findings of this study are available on request.

\section{Conflicts of Interest}

The authors declare that they have no conflicts of interest to this work.

\section{Acknowledgments}

This work was financially supported by the National Natural Science Foundation of China (Grant no. 51804118 and 52074120) and the Fundamental Research Funds for the Central Universities (Grant no. 3142019005), which are gratefully acknowledged.

\section{References}

[1] Y. Chen and S. Chen, Coal Mine Roadway Surrounding Rock Control in China, China University of Mining and Technology Press, Xuzhou, China, 1995.

[2] P. Gou and C. Hou, "Stability analysis of the roof of extraction opening supported with bolts," Ournal of China Coal Society, vol. $24,1999$.

[3] H. Xu, N.-J. Ma, and A.-L. Jia, "Analysis of influence of weak anil terrain thicknesses on feature of strata roof," Rock and Soil Mechanics, vol. 31, 2007.

[4] P. Jia and S. Wang, "Destroy mechanism of tunnelw ith stratified roof," Journal of China Coal Society, vol. 6, 2006.

[5] D. Huang, T.-H. Kang, and K.-L. Duan, "Study on the influence laws of side pressure coefficient on roof failure of roadway in alternating stratified soft," Roof Rock Mining Research and Development, vol. 24, no. 3, 2004.

[6] M. Jia, "A new way of genetic classification on roof falling of bolt supporting roadway," Journal of China Coal Society, vol. 30, no. 5, 2005. 
[7] J. Yang, Study and Application of Roof Stability of Layered Structure of Coal Roadway Supported by Bolt, Beijing University of Science and Technology, Beijing, China, 2002.

[8] X.-H. Chen, H.-H. Shen, and S.-Y. Wang, "The research on theory and influence factors of self-sustaining structure of roadway surrounding rock," Journal of Liaoning Technical University (Natural Science), vol. 21, no. 3, 2002.

[9] D. Chen, X. Hua, Y. Li, and Y. Li, "Study of key technologles and management modes for classifying surrounding of gateway," Chinese Journal of Rock Mechanics and Engineering, vol. 31, no. 11, pp. 2240-2247, 2012.

[10] W. Fei, L. Jie, Z. Quanle, L. Cunbao, C. Jie, and G. Renbo, “A triaxial creep model for salt rocks based on variable-order fractional derivative," Mechanics of Time-Dependent Materials, 2020.

[11] X.-Z. Huang and C.-X. She, "Research on methods of surrounding rock masses stability classification based on extension theory," Rock and Soil Mechanics, vol. 27, no. 10, pp. 1800-1814, 2006.

[12] C. Jiang, M.-H. Zhao, W.-G. Cao et al., "Research on stability evaluation method for cave roof under pile tip in Karst region based on fuzzy theory and catastrophe theory," Journal of Highway and Transportation Research and Development, vol. 25 , no. 12,2008 .

[13] F. Jiang, Z. Mao, Z. Dong et al., "Dynamic and engineering classification of mine road surrounding rock mass," Journal of Engineering Geology, vol. 7, no. 3, pp. 243-249, 1999.

[14] C. Kunfu, J. Hongwen, and H. Lijun, "Classification of roadway surrounding rocks based on field measured ground stress," Journal of Mining \& Safety Engineering, vol. 3, pp. 349-352, 2007.

[15] Z. Nong, W. Cheng, G. Mingshi, and Z. Yiming, "Roadway support diffiulty classification and controlling techniques for Huainan deep coal mining," Chinese Journal of Rock Mechanics and Engineering, vol. 28, no. 12, pp. 2421-2428, 2009.

[16] F. Wu, R. Gao, J. Liu, and C. Li, "New fractional variable-order creep model with short memory," Applied Mathematics and Computation, vol. 380, 2020.

[17] F. Wu, H. Zhang, Q. Zou, C. Li, J. Chen, and R. Gao, "Viscoelastic-plastic damage creep model for salt rock based on fractional derivative theory," Mechanics of Materials, vol. 150, 2020.

[18] X. Yang and H. Wei, "Ratio of internal to external deformation of surrounding rocks and a new kind of classification for tunnel surrounding rocks," Chinese Journal of Geotechnical Engineering, 1998.

[19] B. Zhang, H. Sun, Y. Liang, K. Wang, and Q. Zou, "Characterization and quantification of mining-induced fractures in overlying strata: implications for coalbed methane drainage," Natural Resources Research, vol. 29, pp. 2467-2480, 2019.

[20] Z. Zhang, M. Xu, and Q. Liu, "The research on the methodology of weighted average evaluation for surrounding rock stability of tunnel," Rock and Soil Mechanics, vol. 30, no. 11, pp. 3464-3468, 2009.

[21] Z. Kang, H. Zhou, and X. Feng, "Application of fuzzy analytic hierarchy process to stabilization sort of underground cavern rock," Rock and Soil Mechanics, vol. 27, no. S1, pp. 311-314, 2006.

[22] Y. M. W. Zhu, "Method of support vector machines for classifying surrounding rocks of gateways," Journal of Mining \& Safety Engineering, vol. 23, no. 3, 2006.

[23] Q. Zou, H. Liu, Z. Cheng, T. Zhang, and B. Lin, "Effect of slot inclination angle and borehole-slot ratio on mechanical property of pre-cracked coal: implications for ECBM recovery using hydraulic slotting," Natural Resources Research, vol. 29, no. 3, 2019.

[24] Q. Zou, H. Liu, Y. Zhang, Q. Li, J. Fu, and Q. Hu, "Rationality evaluation of production deployment of outburst-prone coal mines: a case study of nantong coal mine in Chongqing, China," Safety Science, vol. 122, 2020.

[25] X. L. Li, Z. Y. Cao, and Y. L. Xu, "Characteristics and trends of coal mine safety development," Energy Sources, Part A, vol. 15, no. 3, 2020.

[26] S. M. Liu, X. L. Li, D. K. Wang, and D. M. Zhang, "Experimental study on temperature response of different ranks of coal to liquid nitrogen soaking," Natural Resources Research, vol. 30, pp. 1467-1480, 2021.

[27] T. Liu, B. Q. Lin, X. H. Fu et al., "Experimental study on gas diffusion dynamics in fractured coal: a better understanding of gas migration in in-situ coal seam," Energy, vol. 195, 2020.

[28] T. Liu, S. M. Liu, B. Q. Lin et al., "Stress response during insitu gas depletion and its impact on permeability and stability of CBM reservoir," Fuel, vol. 266, 2020.

[29] H. Liu and N. Ma, "Coal mine roadway roof caving high risk areas recognition technology," Journal of China Coal Society, vol. 36, no. 12, 2011.

[30] N. Ma, J. Feng, K. Lyu et al., "Study on cause classification method and support countermeasures of roof falling in coal drift," Coal Science and Technology, vol. 43, no. 6, 2015.

[31] Y.-X. Yu, R.-B. Huang, and B.-Q. Wang, "Analysis on limit equilibrium zone of coal pillar in mining roadway based on mechanical model of elastic foundation beam," Journal of Engineering Mechanics, vol. 142, no. 4, 2016.

[32] S. Hu, F. Zhou, Y. Liu, and T. Xia, "Effective stress and permeability redistributions induced by successive roadway and borehole excavations," Rock Mechanics and Rock Engineering, vol. 48, pp. 319-332, 2015.

[33] F. Jicheng, M. Nian-Jie, C. Meifeng et al., "Application of connected long bolt support in high cutting and narrow coal pillar gateway of deep mine," Coal Science \& Technology, vol. 42, no. 8, 2014.

[34] Z. Z. Ma Nianjie and J. Feng, "Technology of butt long bolt on roadway supporting in difficult conditions," Coal Science and Technology, vol. 41, no. 9, 2013.

[35] D. Park and R. L. Michalowski, "Roof stability in deep rock tunnels," International Journal of Rock Mechanics and Mining Sciences, vol. 124, 2019.

[36] D. Park and R. L. Michalowski, "Three-dimensional roof collapse analysis in circular tunnels in rock," International Journal of Rock Mechanics and Mining Sciences, vol. 128, 2020.

[37] Q. Wang, Z. Jiang, B. Jiang, H. Gao, Y. Huang, and P. Zhang, "Research on an automatic roadway formation method in deep mining areas by roof cutting with high-strength boltgrouting," International Journal of Rock Mechanics and Mining Sciences, vol. 128, 2020.

[38] X. Zhang, R. Y. S. Pak, Y. Gao et al., "Field experiment on directional roof presplitting for pressure relief of retained roadways," International Journal of Rock Mechanics and Mining Sciences, vol. 134, 2020.

[39] T. Zhao and C. Liu, "Roof instability characteristics and pregrouting of the roof caving zone in residual coal mining," Journal of Geophysics and Engineering, vol. 14, no. 6, 2017.

[40] Y. Chen, S. Ma, and Y. Yu, "Stability control of underground roadways subjected to stresses caused by extraction of a 10-mThick coal seam: a case study," Rock Mechanics and Rock Engineering, vol. 50, no. 9, 2017.

[41] P. Cui, B. Yao, Y. Liu et al., "A new width measurement method of the stress relief zone on roadway surrounding 
rocks," Geofluids, vol. 2019, Article ID 9519353, 12 pages, 2019.

[42] Z. Xie, N. Zhang, X. Feng, D. Liang, Q. Wei, and M. Weng, "Investigation on the evolution and control of surrounding rock fracture under different supporting conditions in deep roadway during excavation period," International Journal of Rock Mechanics and Mining Sciences, vol. 123, 2019.

[43] X. Zhang, P. Gong, K. Wang, J. Li, and Y. Jiang, "Characteristic and mechanism of roof fracture ahead of the face in an LTCC panel when passing an abandoned roadway: a case study from the shenghua coal mine, China," Rock Mechanics and Rock Engineering, vol. 52, no. 8, 2019.

[44] Y. Cheng, J. Bai, Y. Ma, J. Sun, Y. Liang, and F. Jiang, "Control mechanism of rock burst in the floor of roadway driven along next goaf in thick coal seam with large obliquity angle in deep well," Shock and Vibration, vol. 2015, Article ID 750807, 10 pages, 2015. 